\title{
Acceleration technique for Milankovitch type forcing in a coupled atmosphere-ocean circulation model: method and application for the Holocene
}

\author{
Stephan J. Lorenz \\ Max-Planck-Institut für Meteorologie, Modelle und Daten, Hamburg, Germany \\ Gerrit Lohmann \\ Universität Bremen, Fachbereich Geowissenschaften and DFG Forschungszentrum Ozeanränder, Bremen, Germany
}

Received: 12 May 2004; accepted: 2 July 2004, published online: 25 August 2004

\begin{abstract}
.
A method is introduced which allows the calculation of long-term climate trends within the framework of a coupled atmosphere-ocean circulation model. The change in the seasonal cycle of incident solar radiation induced by varying orbital parameters has been accelerated by factors of 10 and 100 in order to allow transient simulations over the period from the midHolocene until today, covering the last 7,000 years. In contrast to conventional time-slice experiments, this approach is not restricted to equilibrium simulations and is capable to utilise all available data for validation. We find that opposing Holocene climate trends in tropics and extra-tropics are a robust feature in our experiments. Results from the transient simulations of the mid-Holocene climate at 6,000 years before present show considerable differences to atmosphere-alone model simulations, in particular at high latitudes, attributed to atmosphereocean-sea ice effects. The simulations were extended for the time period 1800 to $2000 \mathrm{AD}$, where, in contrast to the Holocene climate, increased concentrations of greenhouse gases in the atmosphere provide for the strongest driving mechanism. The experiments reveal that a Northern Hemisphere cooling trend over the Holocene is completely cancelled by the warming trend during the last century, which brings the recent global warming into a long-term context.
\end{abstract}

\section{Introduction}

Palaeoclimatic modelling studies, aiming at reconstruction of past climate states, are usually performed either on the basis of time slices or time dependent (transient) simulations. Restricted by computer resources, atmospheric and oceanic general circulation models (AOGCMs) have at first been used to simulate Palaeoclimate time slices allowing for acceptable amounts of computing time (Gates 1976; Manabe and Broccoli 1985; Fichefet et al. 1994). In these types of experiments with component models, boundary conditions have to be prescribed, especially at the surface boundary between atmosphere and ocean (e.g. sea surface temperatures of the last glacial maximum by CLIMAP Project Members (1976)). More recent work is based on coupled models of different complexity, predicting physical quantities such as sea surface temperatures (SSTs) internally (e. g. Ganopolski et al. 1998b; Weaver et al. 1998; Hewitt et al. 2001; Shin et al. 2003). These studies show that the additional feedbacks included are essential for a sound comparison and hence also interpretation of reconstructed data.

However, modelling of time slices cannot provide insights into the temporal evolution of the climate system. The time slices approach implies that the climate is in equilibrium and it cannot shed light on the transient behavior of the climate system. Furthermore, it refers to only a small fraction of the available data. When stepping forward to transient simulations, models of intermediate complexity have been used (e.g., Stocker et al. 1992; Ganopolski and Rahmstorf 2001; Bertrand et al. 2002b; Crucifix et al. 2002; Prange et al. 2003, for a review: Claussen et al. 2002), where the complexity of sub-models is reduced. For example, a statistical and parameterised prescription instead of explicitly resolved internal atmospheric vari-

Latex preprint style (AGU), modified by S. Lorenz, 2004 ability is used, which enables longer simulation times and the analyses of feedback processes by switching on and off the effect of different climatic components.

Recent studies (Keigwin and Pickart 1999; Rimbu et al. 2003) indicated that reconstructed Holocene climate in the North Atlantic realm reflects circulation changes. In order to investigate the dynamic evolution of the atmosphere-ocean system, transient modelling of the Holocene climate with AOGCMs becomes essential for the interpretation of long-term climate change and variability. Motivated by the finding that the atmospheric dynamics (Rimbu et al. 2003) as well as the feedback processes at the atmosphereocean interface may play an active part for climate trends, we use a comprehensive coupled circulation model to simulate long-term temperature trends.

Complementary to previous studies dealing with the climate evolution linked to solar irradiance and volcano forcing (Shindell et al. 1999; Crowley 2000; Shindell et al. 2003), we concentrate on Holocene climate trends induced by the long-term astronomical forcing associated with the varying parameters of the Earth's orbital parameters (Berger 1978). On multi-millennial time scales, the astronomical forcing provides for large imbalances in the seasonal distribution of sun light. Variations of the orbital parameters with higher frequencies are at least two orders of magnitude smaller (Bertrand et al. 2002a), which we do not take into account in this study.

The time scales of the astronomical or "Milankovitch type" forcing are separated from the much shorter time scales of the atmosphere, including the mixed layer of the ocean, by several orders of magnitude. This motivated our idea to accelerate the astronomical forcing, which enables multi-millennial integrations with a fully coupled AOGCM and relatively low computational costs. This method is used to investigate long-term effects of the atmospheresea ice-ocean system induced by the astronomical forcing. Excluded are only those processes that vary on time scales longer than the actual length of the model experiments (decades to centennials). Long-term variations of the ocean circulation on millennial time 
(a) Holocene Insolation at Summer Solstice $\left[\mathrm{Wm}^{-2}\right]$

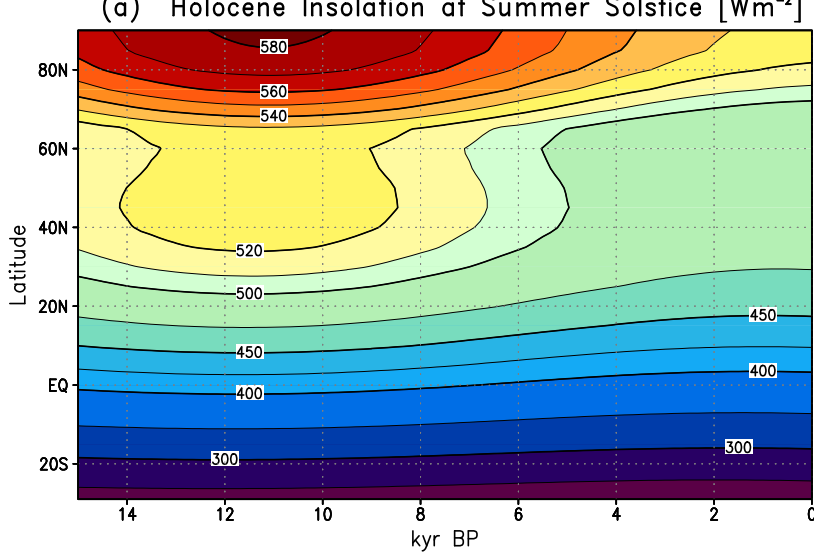

(b) Holocene Insolation at Winter Solstice $\left[\mathrm{Wm}^{-2}\right]$

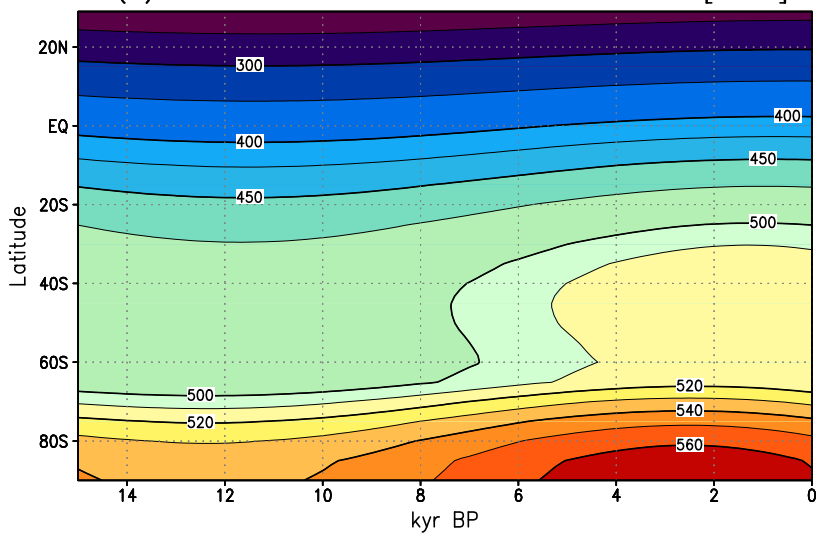

Figure 1. Evolution of the latitudinal distribution of solar radiation for the last $15 \mathrm{kyr}$, following Berger (1978). Shown is the zonal average of insolation at the time of (a) the boreal summer solstice and (b) the boreal winter solstice in $\mathrm{Wm}^{-2}$. Note the different range of latitudes: regions poleward of $20^{\circ}$ of the respective hemisphere with polar night are omitted, where the radiation keeps less than $200 \mathrm{Wm}^{-2}$ and no significant change occurs.

scales, changes in the land ice distribution, as well as long-term sea level variations are not considered in our simulations. Our survey is concerned with the middle to late Holocene, which can be considered as a relatively stable period, wherein rapid climate events were absent (Grootes et al. 1993; Clark et al. 2002).

The temperature evolution of the Holocene is also important in light of recent climate change. The new third assessment report of the Intergovernmental Panel on Climate Change (IPCC 2001) stated a global surface air temperature increase during the past century by $0.6 \pm 0.2$ Kelvin (K). On the longer perspective, the twentieth century warming is likely to be the largest during any century over the past 1,000 years for the Northern Hemisphere, with the 1990s being the warmest decade and 1998 the warmest year of the millennium (Mann et al. 1998; 1999). With our modelling study, we aim to relate the Holocene temperature trends prior to the industrialisation period to the more recent temperature trend over the last century.

Our approach is aimed to simulate the response of the coupled system of atmosphere, ocean and sea ice to astronomical forcing, which sheds light into the transient behavior of the Holocene dynamics. With the continuation of our Holocene experiments into the industrial era, by simulating the recent climate change with increasing greenhouse gas concentration, starting from the background Holocene climate, we want to bring the twentieth century warming trend into the context of the temperature trend over the last 7,000 years. This allows a comparison of astronomically and greenhouse gas induced temperature trends within one AOGCM integration.

The paper is organised as follows: the simulation methods are described in Sect. 2. Here, the coupled model is introduced, and we elucidate our acceleration technique for the Milankovitch type forcing. Furthermore, we explain the model setup used for the ensemble experiments and describe the main forcing by the orbital parameters. In Sect. 3, we present the model results for the Holocene climate trends with different acceleration factors and show the northern high latitude climate in our transient simulations. Additionally, we evaluate and compare the Holocene and recent global warming trends in our simulations. Finally, discussion (Sect. 4) and conclusions (Sect. 5) of our main results are given.

\section{Methodology}

\subsection{The Atmosphere-Ocean circulation model}

For the simulation of the Holocene climate, we use the coupled atmosphere-ocean general circulation model ECHO-G (Legutke and Voss 1999). The atmospheric part of this model is the $4^{t h}$ generation of the European Centre atmospheric model of Hamburg (ECHAM4, Roeckner et al. 1996). The prognostic variables are calculated in the spectral domain with a triangular truncation at wave number 30 (T30), which corresponds to a Gaussian longitudelatitude grid of approximately $3.8^{\circ} \times 3.8^{\circ}$. The vertical domain is represented by 19 hybrid sigma-pressure (terrain following) levels with the highest level at $10 \mathrm{hPa}$. The time step of the atmospheric model is depending on the resolution. Its value is 30 minutes when using T30 resolution. The ECHAM model has been modified with respect to the standard version in order to account for sub-grid scale partial ice cover (Grötzner et al. 1996) that is also considered in the ocean model.

The ECHAM4 model is coupled through the OASIS program (Ocean Atmosphere Sea Ice Soil, Terray et al. 1998) to the HOPE ocean circulation model ( $\underline{H}$ amburg Ocean Primitive Equation model, Wolff et al. 1997). The ocean model includes a dynamicthermodynamic sea-ice model with snow cover. It is discretised on an Arakawa-E grid with a resolution of approximately $2.8^{\circ} \times 2.8^{\circ}$. In the tropics, its meridional resolution is increased to $0.5^{\circ}$. The model consists of 20 irregularly spaced vertical levels with 10 levels covering the upper $300 \mathrm{~m}$. The time step of the ocean model amounts to $2 \mathrm{~h}$.

The model uses annual mean flux corrections for heat and freshwater, applied to the ocean model component. These fluxes are diagnosed from sea surface temperature and salinity restoring terms in a coupled spin-up integration for the current climate (Legutke

Table 1. Names and characteristics of simulations with the ECHO-G model:

\begin{tabular}{|lrrrc|}
\hline $\begin{array}{l}\text { Experiment- } \\
\text { name }\end{array}$ & $\begin{array}{r}\text { PRE- } \\
\text { CTR }\end{array}$ & $\begin{array}{r}\text { HOL- } \\
\text { INS100 }\end{array}$ & $\begin{array}{r}\text { HOL- } \\
\text { INS10 }\end{array}$ & $\begin{array}{r}\text { GHG- } \\
\text { INS1 }\end{array}$ \\
\hline $\begin{array}{l}\text { Acceleration factor } \\
\text { Number of experiments } \\
\text { Integration length }\end{array}$ & 1 & 100 & 10 & 1 \\
\hline Insolation (kyr BP) & 3,000 & 90 & 700 & 200 \\
\hline $\begin{array}{l}\text { Greenhouse gases (AD) } \\
\mathrm{CO}_{2}(\mathrm{ppm})\end{array}$ & 1800 & 1800 & 1800 & $1800-2000$ \\
$\mathrm{CH}_{4}(\mathrm{ppb})$ & 280 & 280 & 280 & $280-370$ \\
$\mathrm{~N}_{2} \mathrm{O}(\mathrm{ppb})$ & 700 & 700 & 700 & $700-1715$ \\
\hline
\end{tabular}



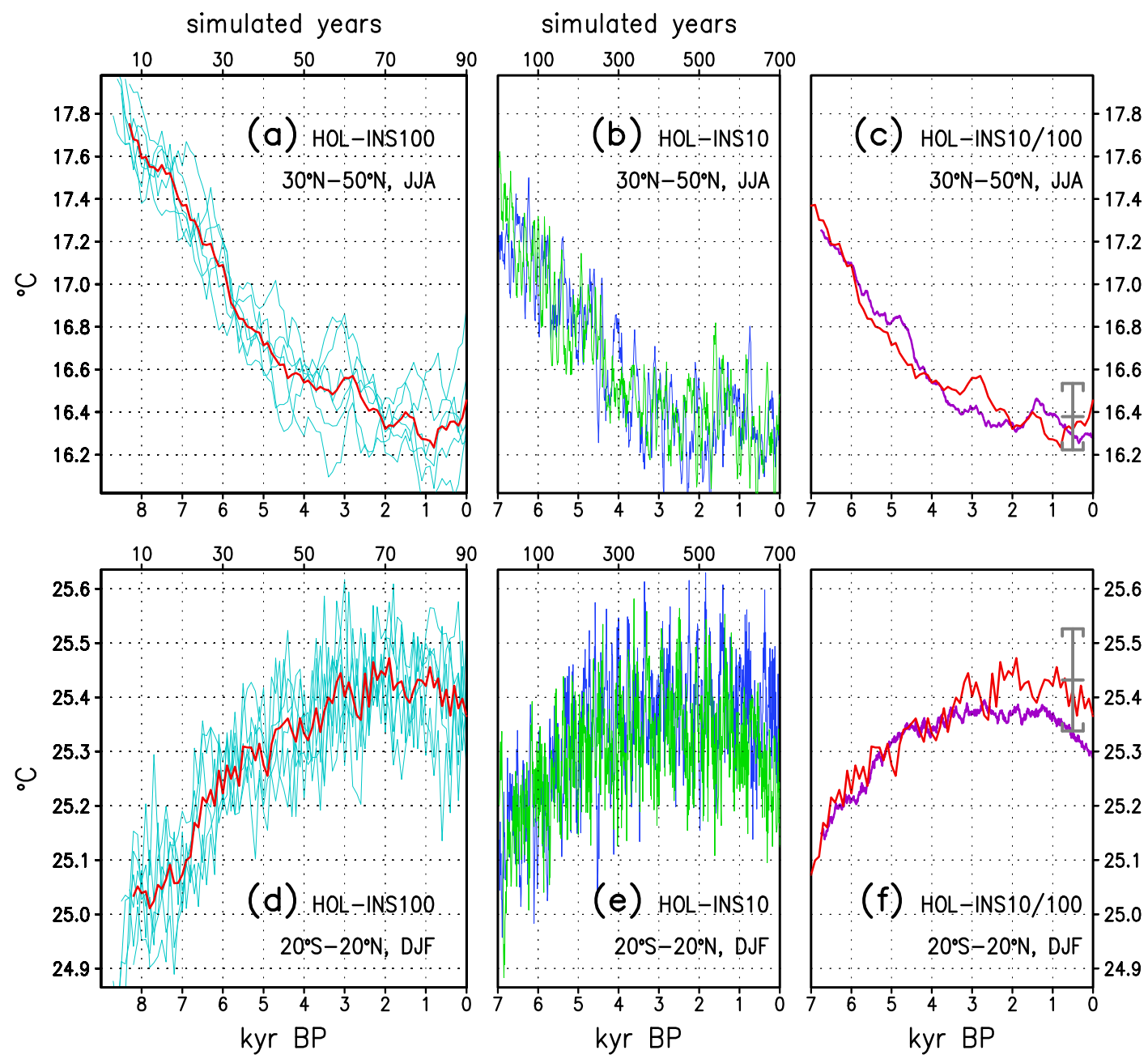

Figure 2. Holocene surface temperature at $(a-c)$ northern mid-latitudes during boreal summer season, and $(d-f)$ in the tropics during boreal winter, simulated with the ECHO-G model. The red lines display the ensemble mean of the six individual experiments (HOL-INS100, thin blue lines) using an acceleration factor of 100 for the orbital forcing: 70 years of model integration (from modelled year 20 to 90, upper axis labels) comprise the time span of the last 7,000 years (lower axis labels). The blue and green line in (b) and (e) are two realisations of Holocene experiments using an acceleration factor of 10 (HOL-INS10), i. e. 700 simulation years. For comparison the ensemble means of both sets of experiments are shown together (red: HOL-INS100, purple: HOL-INS10) in (c) and (f). A 5-year running mean is used as a low-pass filter for all experiments, except for the purple line in (c) and (f) where a 50-year filter is used. The error bars indicate $2 \sigma$ standard deviations of the control experiment PRE-CTR (years 1,000-1,500), calculated using a 5-year running mean. The real time axes on all panels utilise the same scaling for $1 \mathrm{kyr}$.

and Voss 1999), using present boundary conditions (e.g., 353 ppm $\mathrm{CO}_{2}$ concentration in the atmosphere) and climatologies. The fluxes are constant in time and their global integral over the ocean has no sources or sinks of energy and mass. Although the use of flux corrections is not ideal for climate simulations strongly deviating from the present climate, they are utilised even in model simulations of a glacial climate (e. g. Kitoh and Murakami 2002; Kim et al. 2002). Due to the similiarity of the Holocene and present climate, the use of flux corrections in our simulations is less problematic. The coupled model has been used in a number of climate variability studies on various time scales (e. g., Raible et al. 2001; Zorita et al. 2003; Rodgers et al. 2004).

\subsection{Orbital forcing}

The ECHO-G model has been adapted to account for the influence of variations in the annual distribution of solar radiation due to the slowly varying orbital parameters: the eccentricity of the Earth's orbit, the angle between the vernal equinox and the perihelion on the orbit, as well as the obliquity, i. e. the angle of the Earth's ro- tation axis with the normal on the orbit. These parameters cause the astronomical or Milankovitch-forcing (Milankovitch 1941; Imbrie et al. 1992) of the climate system. Here, it should be noted that the seasonal distribution of insolation at the outer boundary of the atmosphere is independent of the variability of the solar constant, which is linked to the Sun's output of radiation (e. g. Hoyt and Schatten 1993; Lean and Rind 1998). Such variations in the solar output as well as shortened insolation due to volcanic eruptions are not taken into account, since no continuous data apart from the last millennium (Crowley 2000) exist. The calculation of the orbital parameters follows Berger (1978). They are used in the ECHAM model to evaluate the seasonal cycle of incoming solar radiation.

Fig. 1 shows the changing solar irradiance due to the slowly evolving orbital parameters during the last 15,000 years at the (boreal) summer solstice (Fig. 1a) and the winter solstice (Fig. 1b), respectively. While the insolation is very similar to today during the last glacial maximum at 21,000 years before present (abbreviated as kyr BP in the following), it achieves its maximum deviation from today between 13 and $9 \mathrm{kyr}$ BP at Northern Hemisphere summer solstice. This is due to both, a larger tilt of the Earth's rotation axis 


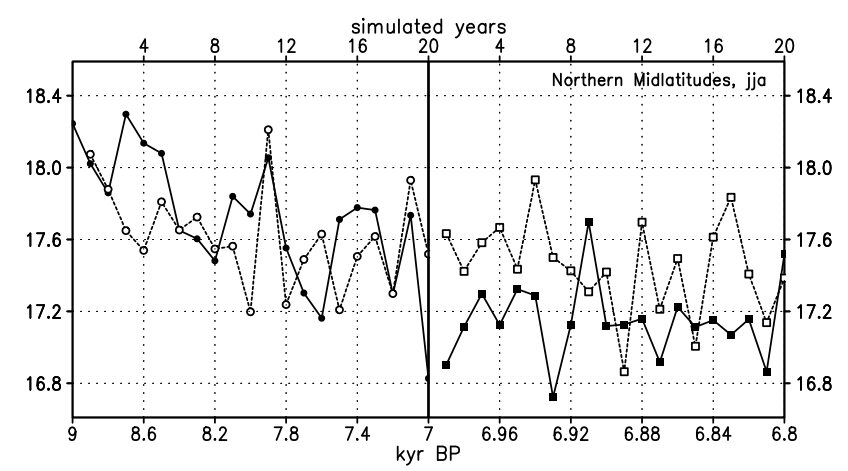

Figure 3. Summer surface temperature (in ${ }^{\circ} \mathrm{C}$ ) of northern midlatitudes (cf. Fig. 2a) of two experiments of HOL-INS100 and the continuation of these experiments with HOL-INS10 at $7 \mathrm{kyr}$ BP where the acceleration factor for the orbital forcing changes from 100 to 10 . Shown are 3-monthly means of single model years, no running mean filter is applied. Note the change in the scaling of the real time axis belonging to the change in the acceleration factor.

and the precession cycle, moving the passage of the Earth through its perihelion from boreal summer in early Holocene to begin of January today. At the winter solstice (Fig. 1b), a lack of insolation during early to mid-Holocene compared to today is centred around the equator. This is mainly affected by the precession cycle, since the distance to the sun was at maximum in boreal winter at middle Holocene. At $3 \mathrm{kyr} \mathrm{BP}$, the insolation reaches nearly the present energy level.

\subsection{Acceleration technique}

Computer resources to run a complex model like the ECHO$\mathrm{G}$ over the time period of the Holocene are very demanding: For example, the ECHO-G model consumes around 3 CPU-hours computing time for one simulation year on the present NEC SX-6 machine using a single $\mathrm{CPU}$ at the German Climate Computing Centre (DKRZ), where the calculations have been conducted. In order to save computational costs, the time scale of the astronomical forcing has been shortened in different experiments. For the simulation of the Holocene climate we perform two sets of experiments, where we use two different acceleration factors of 10 and 100 for the orbital forcing: for each simulated year we calculate stepwise the respective orbital parameters, which are the basis for the calculation of the seasonal cycle of insolation. The subsequently simulated year is then forced by orbital parameters calculated from the next decade (century) of the Holocene, when utilising a factor of 10 (100) for the accelerated Milankovitch forcing. The stepwise change in seasonal insolation is small (less than $1 \mathrm{Wm}^{-2}$ at maximum equatorwards of $65^{\circ}$ with the acceleration factor 100) compared to the seasonal cycle.

The underlying assumptions of our procedure are twofold: (1) the astronomical Milankovitch type forcing operates on much longer time scales (millennia) than those inherent in the atmosphere including the mixed layer of the ocean (months to a few years), and (2) climatic changes related to long-term variability of the thermohaline circulation during the considered time period are small in comparison with surface temperature trends. With this method the simulations with the fully coupled AOGCM capture feedbacks and variabilities of the atmosphere-ocean system with time scales up to decades or centennials, depending on the actual length of the model experiment. The insolation trends of the last 7,000 years are represented in 70 and 700 simulation years, respectively.

\subsection{Model experiments}

\subsubsection{Pre-industrial control experiment}

We perform an experiment for pre-industrial climate conditions that serves as a basic state for our Holocene and greenhouse gas scenario experiments. Control experiments usually prescribe values of atmospheric greenhouse gases valid for the last decade, including a $\mathrm{CO}_{2}$ concentration between 350 and $370 \mathrm{ppm}$ (e.g. Boville and Gent 1998; Hewitt et al. 2001). Here, we utilise concentrations of the main three greenhouse gases (carbon dioxide, methane, and nitrous oxide) typical for the pre-industrial era of the latest Holocene (end of eighteenth century): $280 \mathrm{ppm} \mathrm{CO}_{2}, 700 \mathrm{ppb} \mathrm{CH}_{4}$, and $265 \mathrm{ppb} \mathrm{N}_{2} \mathrm{O}$. Other boundary conditions are the vegetation ratio, surface background albedo, and the distribution of continents and oceans. These quantities are derived from modern worldwide measurements and kept constant throughout the simulation (Roeckner et al. 1996). Modern solar radiation has been prescribed for the control experiment, abbreviated as PRE-CTR (Tab. 1).

This control experiment has been integrated over 3,000 years of model simulation into a climate state that is regarded as the quasiequilibrium response of the model to pre-industrial boundary conditions prior to the perturbation by the anthropogenic emissions of greenhouse gases. The transient simulations of the Holocene climate use the quasi-equilibrium state after 1250 simulation years of this experiment for their initial conditions. In the subsequent 600 years, the control integration exhibits a global surface temperature reduction of $0.018 \mathrm{~K}$ per century, which is mainly due to an artificial increase of the Southern Hemisphere sea ice (see Sect. 3.1). North of $40^{\circ} \mathrm{S}$, the cooling trend is less than $0.008 \mathrm{~K}$ per century.

\subsubsection{Transient Holocene experiments}

In order to isolate the Milankovitch-effect on the Holocene climate we neglect small changes in greenhouse gases in our Holocene experiments and prescribe constantly the same pre-industrial concentrations as for the control experiment PRE-CTR. The variability of the three gases during the Holocene is relatively small compared to that of the last ice age or compared to the increase during the twentieth century. For example, the fluctuation of $\mathrm{CO}_{2}$ during the last 7,000 years has a maximal range between 265 and 285 ppm (Indermühle et al. 1999). All other boundary conditions (vegetation, distribution of land and oceans, etc.) remain unchanged compared to the control experiment (PRE-CTR) and for the Holocene experiments.

We perform two sets of transient experiments to simulate the Holocene climate evolution. The first set of ensemble experiments consists of six model runs over 90 simulation years, representing the

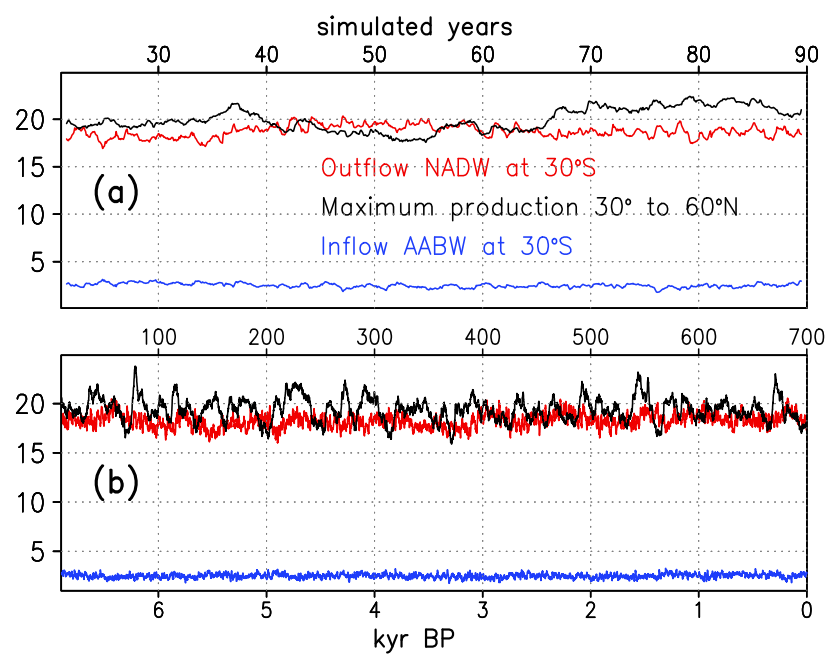

Figure 5. Measure of the meridional overturning circulation in the Atlantic Ocean during the Holocene from one of the experiments (a) HOL-INS100 with 70 years integration time, and (b) one of HOL-INS10 with 700 years integration time, respectively. Note the different scaling in the integration time axis (upper axis) in (a) and (b). Maximum production rate of North Atlantic deep water (NADW) and its export rate into the Southern Ocean. Also shown is the inflow (positive) of Antarctic bottom water (AABW) into the North Atlantic Ocean. Values are in Sverdrup $\left(1 \mathrm{~Sv}=1 \cdot 10^{6} \mathrm{~m}^{3} \mathrm{~s}^{-1}\right)$. 

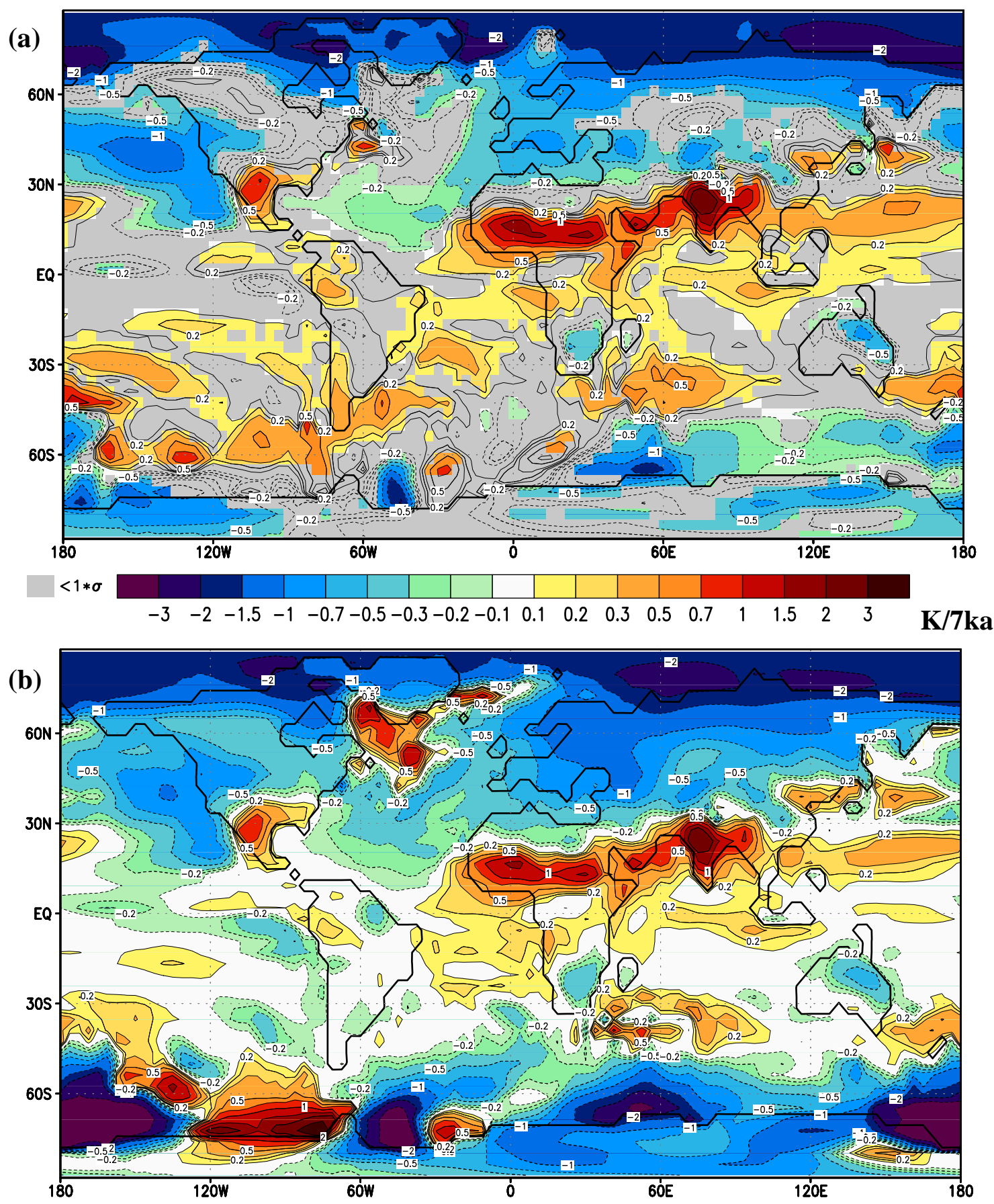

Figure 4. Mean surface temperature trend from the mid-Holocene into the pre-industrial era (from 7 kyr BP to 0 kyr BP) of (a) HOL-INS100 (70 simulation years) and (b) HOL-INS10 (700 simulation years). Values depict the trend over the whole period (Kelvin per $7 \mathrm{kyr}$ ) statistically evaluated from the averaged set of experiments. Regions where the trend does not exceed one standard deviation are grey shaded in (a). Due to two realisations only, shading is omitted in (b). The pattern correlation coefficient between both data sets, calculated on grid points where the trend exceeds one standard deviation in (a), amounts to 0.64 .

last 9,000 years, using an acceleration factor of 100 (experiments HOL-INS100). In this ensemble, all experiments are set up with different initial conditions in the atmosphere-ocean system, given by subsequent years of the control integration (PRE-CTR), the end of the years 1249 to 1254 , respectively. The experiments start after 1250 simulation years of the control experiment, when the coupled system including the deep ocean is regarded to be in a quasi-equilibrium with the pre-industrial boundary conditions and modern insolation. The experiments HOL-INS100 are then instantaneously forced with the varying insolation beginning with $9 \mathrm{kyr}$ BP. The first 20 years of the simulations are taken as spin-up time for the atmospheric model coupled with the mixed layer of the ocean model but excluding the deep ocean to adapt to the changed insolation distribution. The following 70 years of model integration are analysed, reflecting the time evolution of the mid-to-late Holocene, the last 7,000 years.

In order to test the effect of the acceleration technique we perform a second set of simulations of the Holocene. It consists of two experiments using the acceleration factor of 10 , instead of 100 (experiments HOL-INS10). These two model simulations are associ- 

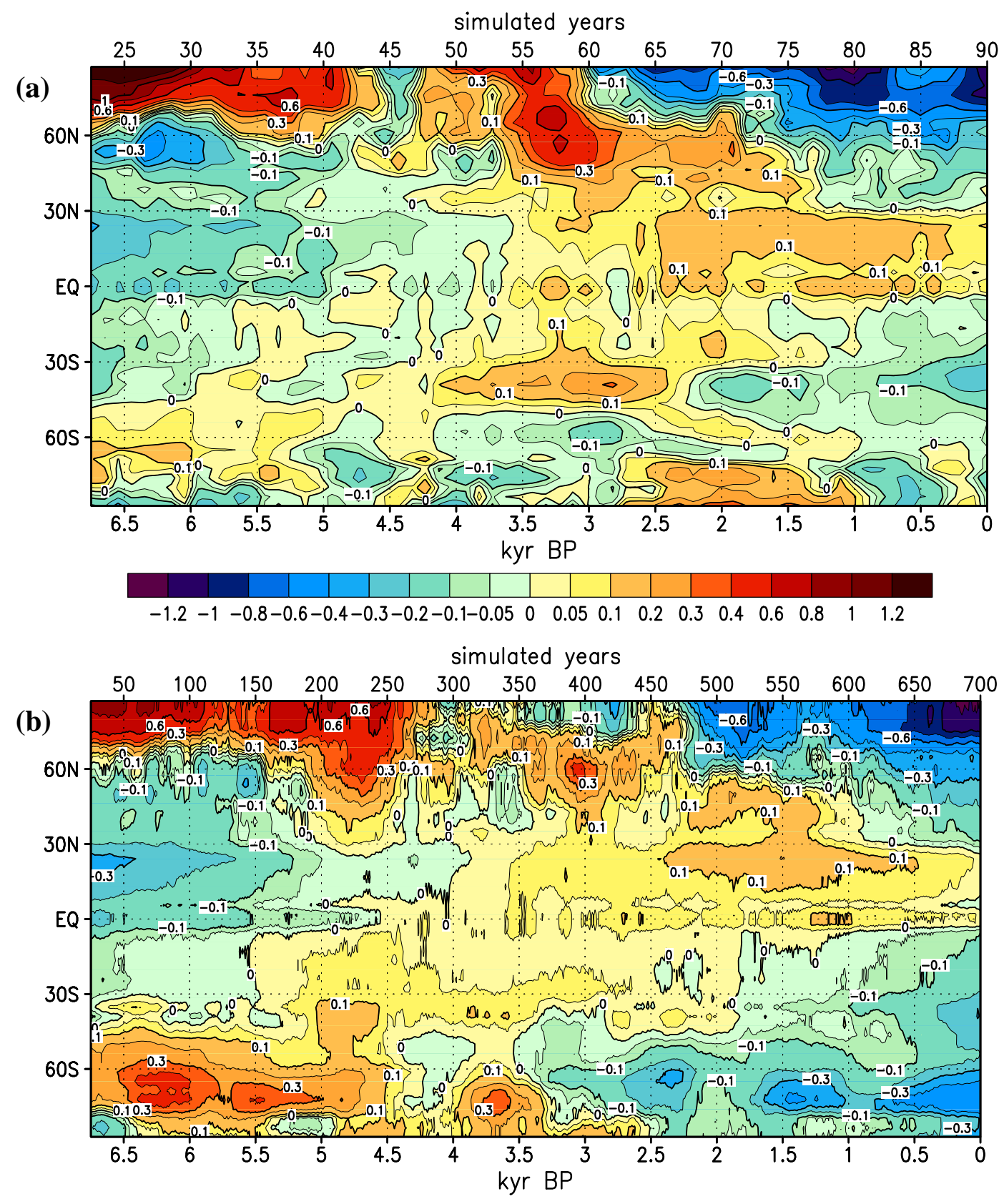

Figure 6. Temporal evolution of zonal mean surface temperature anomaly (in K) during boreal winter from the mid-Holocene into the pre-industrial era of experiments HOL-INS100 (a) and HOL-INS10 (b). The respective long-term zonal mean is subtracted and a running mean filter of 4 years (a) and 50 years (b) is applied, respectively. For the axes scaling cf. Fig. 2 and Fig. 5.

ated to 700 model years which simulate the orbitally forced climate change during the last 7,000 years. The experiments start after the 20 year spin-up time of the first set of Holocene experiments (HOLINS100, Tab. 1). In the initial year after this spin-up time, orbitally defined at $7 \mathrm{kyr}$ BP, the new experiments HOL-INS10 are forced with an annual cycle of insolation identical to that of experiments HOLINS100.

\subsubsection{Greenhouse gas experiments}

For a comparison of the orbital forced temperature with the effect by the anthropogenically induced increase of greenhouse gases we perform another set of experiments. The two experiments HOLINS10 are continued to simulate the period from the year 1800 to $2000 \mathrm{AD}$, without using the acceleration technique (factor 1, GHGINS1). They initialise at $0.2 \mathrm{kyr} \mathrm{BP}$ of experiments HOL-INS10 and are forced with both, transient orbital forcing and the historical records of greenhouse gases for the last two centuries. The concentration of the three main greenhouse gases $\left(\mathrm{CO}_{2}, \mathrm{CH}_{4}\right.$ and $\mathrm{N}_{2} \mathrm{O}$; the most prominent $\mathrm{CFCs}$ and their increase are taken into account) during the last two centuries have been compiled (a compendium: Boden et al. 1994) from ice core and instrumental records (e. g. Etheridge et al. 1996; 1998; Sowers et al. 2003). Direct and indirect aerosol effects are not included in the depicted experiments with the ECHO-G model.

\section{Results}

For our analysis of the experiments HOL-INS100 we use the ensemble mean of the six experiments in order to evaluate the trend 
(a) $2 \mathrm{~m}$ temperature $\left[{ }^{\circ} \mathrm{C}\right] 6 \mathrm{~K}$

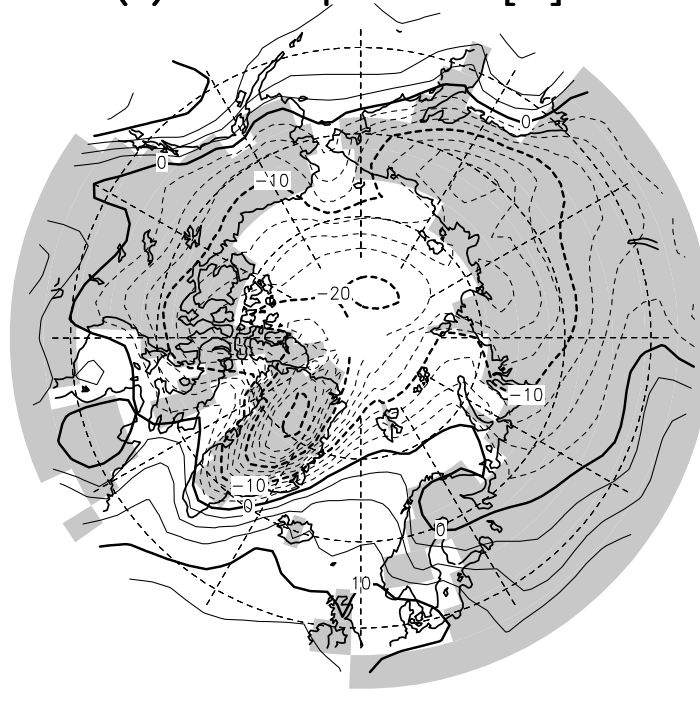

(c) sea ice depth $[\mathrm{m}] 6 \mathrm{~K}$

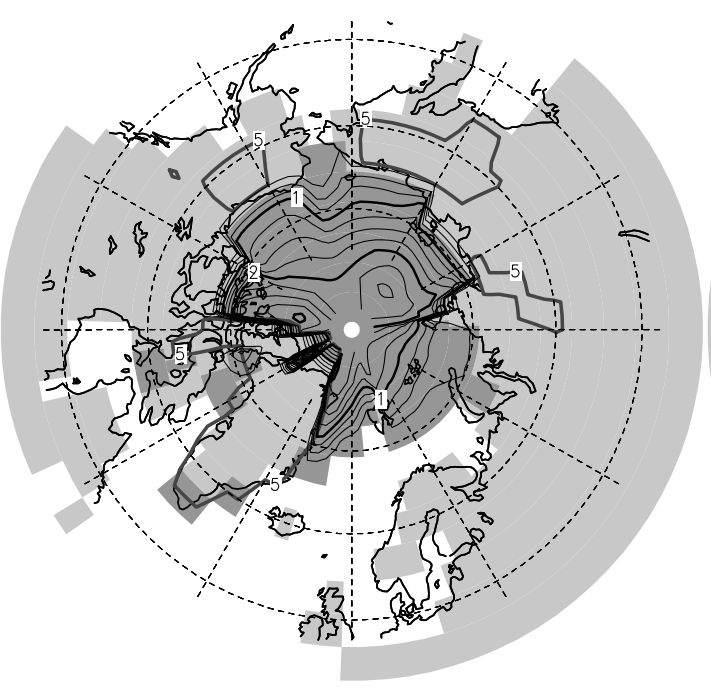

(b) anomaly $6 \mathrm{~K}-\mathrm{OK}$

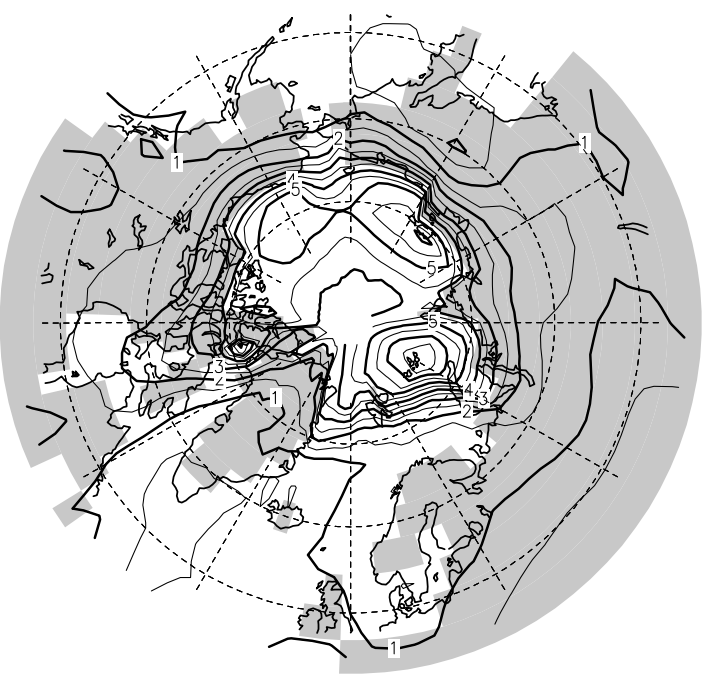

(d) anomaly $6 \mathrm{~K}-\mathrm{OK}$

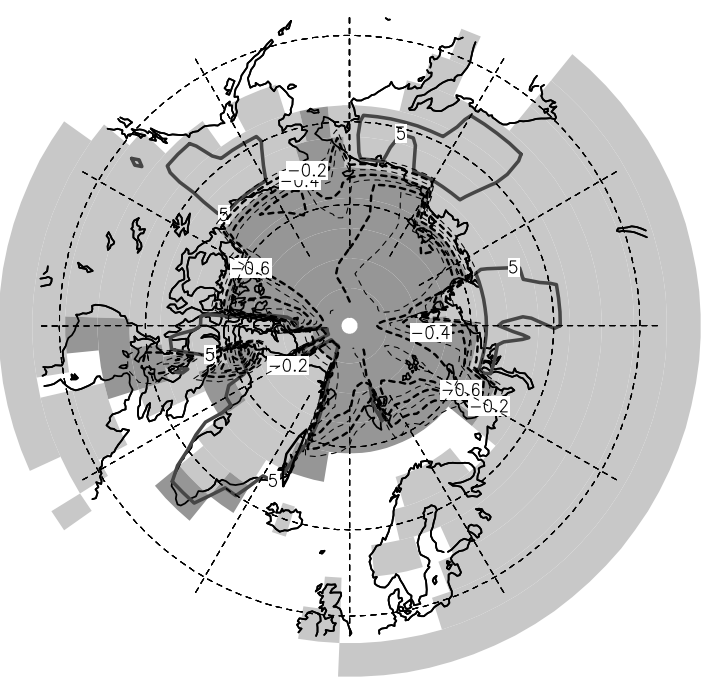

Figure 7. Near surface air temperature (a), sea ice thickness and compactness (c) in October for the mid-Holocene climate at 6 kyr BP; surface air temperature (b) and sea ice thickness (d) difference between the mid-Holocene and the pre-industrial climate. Areas where sea ice compactness exceeds $20 \%$ are darkly shaded for $6 \mathrm{kyr}$ BP in (c) and for $0 \mathrm{kyr} \mathrm{BP}$ in (d) (no difference). Additionally, the $5 \mathrm{~cm}$ contour line for snow depth is indicated with a thick grey line for $6 \mathrm{kyr}$ BP in (c) and $0 \mathrm{kyr}$ BP in (d) (no difference). Light shading indicates continents in the T30 resolution of the atmospheric sub-model ECHAM. Displayed is experiment HOL-INS10 for October, where $6 \mathrm{kyr}$ BP is a mean of 60 years between 5.7 and $6.3 \mathrm{kyr} \mathrm{BP}$, and $0 \mathrm{kyr} \mathrm{BP}$ is a similar average around the pre-industrial climate (1800 AD). The contour intervals for temperature (sea ice thickness) are $2.5 \mathrm{~K}(0.25 \mathrm{~m})$ and $0.5 \mathrm{~K}(0.1 \mathrm{~m})$ for anomalies, respectively.

and the standard deviation over the last 70 simulation years after the spin-up time. Due to the inherent noise of the system, all experiments exhibit independent realisations of the orbitally forced Holocene climate evolution. The ensemble mean for this period is damped by averaging over the six experiments. For the experiments HOL-INS10 we used the complete 700 simulation years long period of the two experiments to evaluate the Holocene climate trend. Since the average of the simulated climate evolution consists of two realisations only, the mean variability of this time series is higher than the ensemble mean of HOL-INS100.

\subsection{Surface temperature trends}

In Fig. 2, we present the evolution of regional surface temperature indices for the two sets of experiments HOL-INS100 (Fig. 2a, d) and HOL-INS10 (Fig. 2b, e), respectively. The experiments represent the time span from the mid-Holocene to the pre-industrial climate (lower axis labelling) with their integration time of 90 and 700 model years, respectively (upper axis labelling). Shown are regional averages over surface temperatures, where SST over ice free water is taken. Elsewhere, ground, ice and snow temperatures are considered.

The ensemble simulations performed with the ECHO-G model exhibit significant surface temperature trends during the middle to late Holocene. The orbital induced signal of decreased boreal summer insolation in northern mid and high latitudes (Fig. 1a) is represented by a surface temperature drop of $1.4 \mathrm{~K}$ between $30^{\circ} \mathrm{N}$ and $50^{\circ} \mathrm{N}$ during the last 7,000 years (Fig. $2 \mathrm{a}-\mathrm{c}$ ). In the tropics, a rise in simulated surface temperature of $0.4 \mathrm{~K}$ is found in boreal winter season (Fig. 2d-f) in accordance with the observed increasing tropical solar radiation during the Holocene (Fig. 1b). 
The shape of the temperature trends is similar in the two different sets of experiments (Fig. 2c, f): there is a strong decrease in northern mid-latitudes (Fig. 2c) and an increase in low latitudes (Fig. 2d) between 7 and 4 kyr BP. After 4 kyr BP, the trends are weaker due to relatively small variations in solar radiation relative to the midHolocene period (Fig. 1). Within the last 1,000 to 2,000 years, the trends indicate a moderate cooling in the tropics or nearly vanish at mid-latitudes. These characteristics are analogue in the ensemble mean curves of experiments HOL-INS100 (red line in Fig. 2c, f), and in experiments HOL-INS10 (purple line in Fig. 2c, f).

We examine the transition at $7 \mathrm{kyr}$ BP between our different experiments when changing the acceleration factor from 100 to 10 (Fig. 3). Apart from the inter-annual variability, there is no remarkable change in the temperature evolution. A comparison with Fig. 2a-c indicates that the temperature trend, induced by the insolation change due to the orbital forcing, remains unchanged.

For our two sets of Holocene simulations, we evaluate the spatial distribution of the annual mean temperature trend (Fig. 4). A general agreement in the spatial distribution of the surface temperature trends is detected between HOL-INS100 and HOL-INS10 (the spatial correlation coefficient amounts to 0.64, cf. Fig. 4). The SST in the tropical region shows an increase from the middle to the late Holocene.

The most pronounced temperature trends occur over the continents. The smaller heat capacity compared to the ocean induces an amplification of the temperature trends. Enhanced warming during the Holocene occurs in the arid subtropical continents from northern Africa via western Asia to the Indian subcontinent. The most distinct cooling takes place over continental and sea ice covered northern high latitudes, exceeding $2 \mathrm{~K}$ temperature drop in both sets of experiments. We find that the trend is robust against the choice of ensemble members, showing that the difference in the inter-annual variability of both sets of experiments has no significant effect on the amplitude and distribution of the regional trends.

The temperature trends in the North Atlantic realm indicate both positive and negative values: a continuous cooling in the northeastern Atlantic is accompanied by a continuous warming in large areas

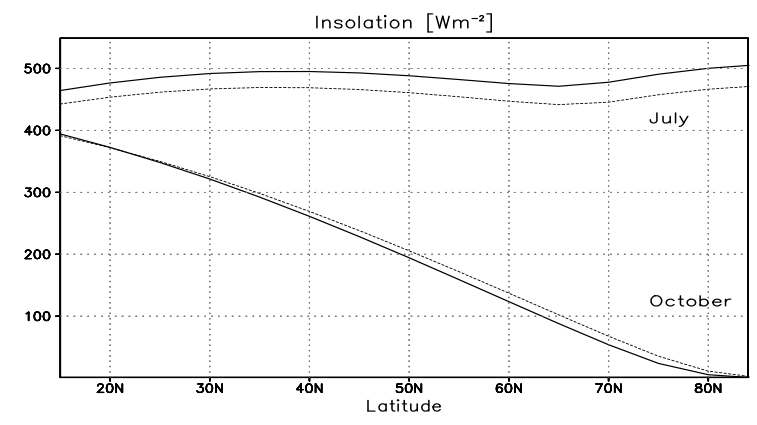

Figure 8. Latitudinal distribution of solar radiation during the mid-Holocene (6 kyr BP, solid line) compared to the present radiation (dashed line) in July and October (Berger 1978).

of the subtropical Atlantic Ocean, as well as in the northwestern Atlantic off Newfoundland (Fig. 4a), the Labrador Sea and south of Greenland (Fig. 4b). Moreover, the Labrador realm shows a strong positive trend (Fig. 4b), but is also a region of high variability, due to varying convection sites on multi-decadal time scales (note the shading in Fig. 4a, indicating a high noise level in HOL-INS100). These stochastic convective events are the main reason for differences between the two 700 simulation years long realisations of the Holocene climate in the Labrador Sea (not shown).

The largest mismatches between experiments HOL-INS100 and HOL-INS10 are located near the sea ice margins north of the Antarctic and in small regions in the northern North Atlantic Ocean. There are matching and mismatching dipole structures in the Antarctic Circumpolar Current. Here, the model results are less reliable than on the Northern Hemisphere: the sea ice thickness is much smaller than observed, which is a prevalent drawback in coupled climate models (Marsland et al. 2003, Legutke, pers. comm.). We note that this (a) $10 \mathrm{~m}$ Wind $[\mathrm{m} / \mathrm{s}] 6 \mathrm{~K}$
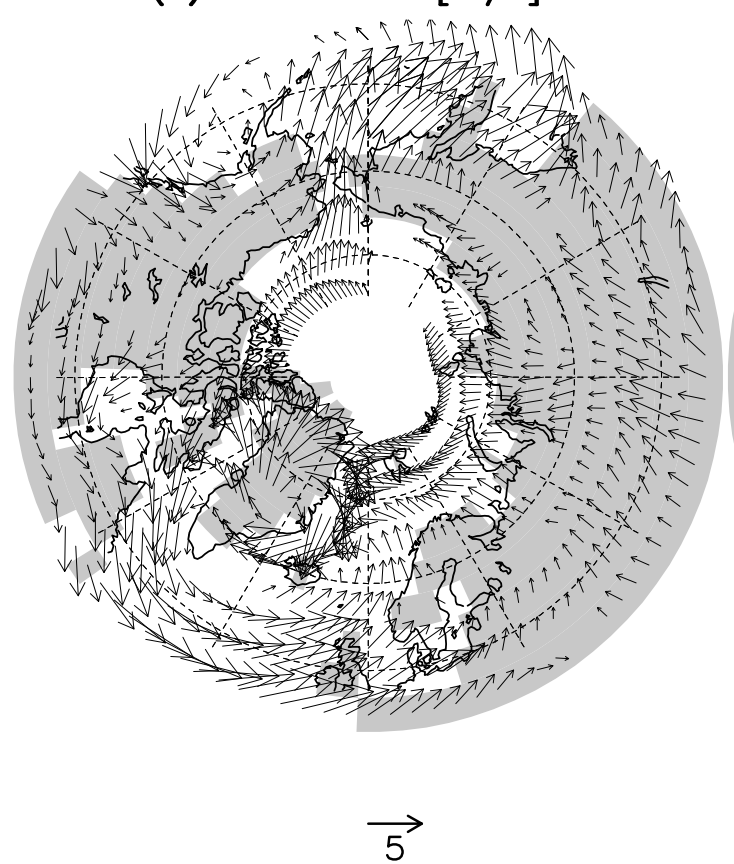

(b) anomaly $6 \mathrm{~K}-\mathrm{OK}$

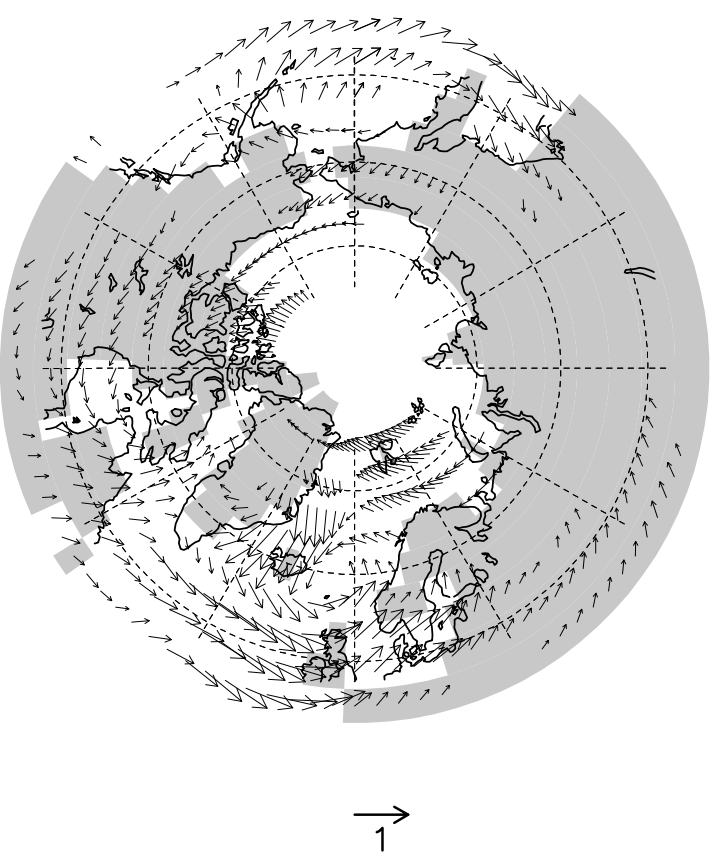

Figure 9. Surface wind (a) during boreal winter season (January to March) for the mid-Holocene climate at 6 kyr BP and wind anomaly (b) of the mid-Holocene from the pre-industrial climate (for details see Fig. 7). The arrows below indicate the strength of the respective wind speed (in $\mathrm{m} / \mathrm{s}$ ). Vectors with a magnitude less than $1 \mathrm{~m} / \mathrm{s}$ and $0.2 \mathrm{~m} / \mathrm{s}$ are omitted in (a) and (b), respectively. 
model deficiency is also responsible for the spurious trend south of $40^{\circ} \mathrm{S}$ in the control experiment.

In order to estimate the orbital irradiation effect on the thermohaline circulation, the meridional mass transport in the Atlantic Ocean is evaluated for the two sets of experiments. For this purpose, we show indices of the meridional stream function (Fig. 5): the maximal overturning in the North Atlantic Ocean (between $30^{\circ} \mathrm{N}$ and $60^{\circ} \mathrm{N}$, below $1,000 \mathrm{~m}$ depth), the export of deep water into the Southern Ocean at $30^{\circ} \mathrm{S}$, and the import of Antarctic Bottom Water into the Atlantic Ocean at the same latitude. From Fig. 5, it can be deduced that the meridional overturning circulation is nearly unchanged throughout the Holocene experiments. This is, a posteriori, an indication for the valid assumption of a relatively stable thermohaline circulation during the middle to late Holocene.

The evolution of the zonal mean surface temperature in the boreal winter season during the Holocene is displayed in Fig. 6, where the deviation of each of the two sets of Holocene experiments from its respective zonal average of the entire time series are taken. Except for the region south of $40^{\circ} \mathrm{S}$, the similarities between the two sets are evident: a moderate warming in low latitudes (cf. Fig. 2f) and the strongest cooling of more than $1.5 \mathrm{~K}$ in the Arctic. Between 4 kyr BP and 2 kyr BP we find a warm phase widespread into the northern mid to high latitudes, which is especially located over the North American and Eurasian continents (Lohmann et al. 2004). Interestingly, in experiments HOL-INS100 as well as in HOL-INS10, the tropical warming is compensated by the cooling signal coming from the high latitudes during the last two millennia. This feature is evident in both sets of simulations indicating that it is not linked to internal multi-decadal variability of the atmosphere-ocean-sea ice system.

\subsection{Mid-Holocene climate}

Motivated by the Palaeoclimate Modeling Intercomparison Project (PMIP, Joussaume and Taylor 2000), we evaluate the climate of the time slice at the mid-Holocene optimum (6 kyr BP) in comparison to the pre-industrial climate. The PMIP project has fostered a systematic evaluation of climate models, besides others, under conditions during the mid-Holocene. This time slice was chosen to test the near-equilibrium response of climate models to orbital forcing at the so-called Holocene Climate Optimum with $\mathrm{CO}_{2}$ concentration and ice sheets at pre-industrial conditions. The dating of this time slice was selected to $6 \mathrm{kyr}$ BP because at this time no remaining melting ice caps were present, which may have survived the deglaciation phase at the early Holocene period.

We analyse averages of 60 simulation years out of 700 years of experiments HOL-INS10, centred at $6 \mathrm{kyr} \mathrm{BP}$ and $0 \mathrm{kyr} \mathrm{BP}$, respectively. The latter time slice in our transient simulation characterises the pre-industrial climate. We find that the largest Northern Hemisphere temperature difference between the two time slices occurs in October. For October, we display the simulated surface temperature of the mid-Holocene climate and its deviation from the pre-industrial climate (Fig. 7a,b), as well as sea ice thickness and its anomaly (Fig. 7c, d). Note that in this section we present differences of the mid-Holocene climate from the latest Holocene and that a positve anomaly in Fig. 7b indicates warmer temperatures at $6 \mathrm{kyr} \mathrm{BP}$, which is concordant with a cooling trend during the last 6,000 years (Fig. 4).

A region of warmer temperature $(3-6 \mathrm{~K})$ during the midHolocene compared to the latest Holocene is located over the entire Arctic Ocean (Fig. 7b), accompanied by a decrease of the Arctic sea ice thickness of 40 to $80 \mathrm{~cm}$ (Fig. 7d). The maximum anomalies are located in the Laptev Sea, in the Labrador Sea and near Svalbard. In these regions the temperature anomaly exceeds $6 \mathrm{~K}$ and the sea ice reduction amounts to more than $80 \mathrm{~cm}$ in the same areas. Note also a reduction in sea ice extent in the mid-Holocene simulation in Hudson Bay, Greenland Sea, Barents and Bering Sea, compared to $0 \mathrm{kyr}$ BP (dark shaded area with sea ice compactness of more than $20 \%$ for 6 kyr BP in Fig. 7c, and for 0 kyr BP in Fig. 7d). Similarly, a reduction in the snow covered area in central Siberia,

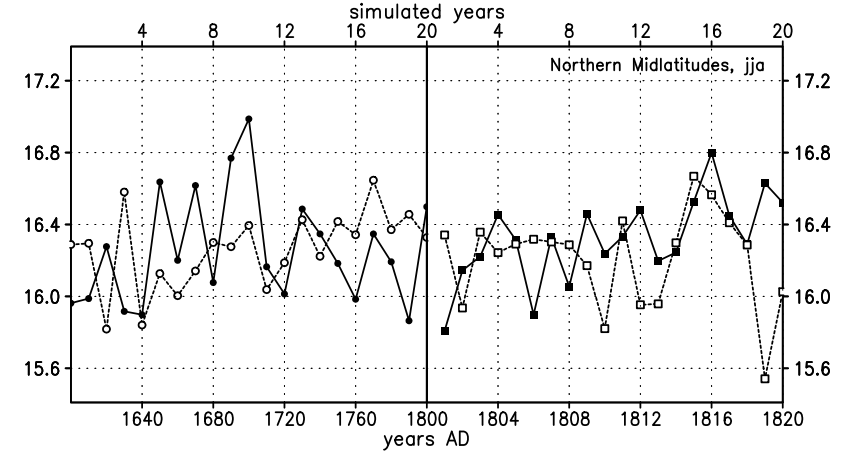

Figure 10. Summer surface temperature (in ${ }^{\circ} \mathrm{C}$ ) of northern mid-latitudes (cf. Fig. 2a) of two experiments of HOL-INS10 and the continuation of these experiments with GHG-INS1 at the year $1800 \mathrm{AD}$ where the acceleration factor for the orbital forcing varies from 10 to 1 (no acceleration). See text and Fig. 3 for details.

eastern Siberia, and Alaska can be detected from the $5 \mathrm{~cm}$ snow depth contour line in Fig. 7c and Fig. 7d.

The temperature change indicates a strong nonlinear signal in the model response to the radiative forcing: the solar radiation at 6 kyr BP during October, when the most intense warming takes place, has an energy deficit of $15 \mathrm{Wm}^{-2}$ at $60^{\circ} \mathrm{N}$ compared to today (Fig. 8). The heat capacity of the upper ocean stores the warming of the boreal summer insolation, i. e. $30 \mathrm{Wm}^{-2}$ more energy input than today in the Arctic from mid of June to end of July (Fig. 8). The warmer SST during the summer season with high level energy input lengthens the ice free season, reduces average sea ice thickness as well as snow depth in the neighbouring northern continents in October. This occurs despite the fact that the seasonal radiation anomaly has already turned its sign. Therefore, the sea ice and snow cover indicate a delayed response of the climate to the Milankovitch forcing.

The model simulates also modified surface winds during midHolocene boreal winter in the Arctic region (Fig. 9). We find enhanced southward winds in the western part of the Greenland Sea and the region south of Greenland and Iceland. Furthermore, there is intensified cyclonic circulation in the Norwegian Sea. This is consistent with an increased eastward wind pattern during 6 kyr BP relative to the pre-industrial climate. The wind affects the sea ice dynamics in these regions and, in particular, enhance southward sea ice transport along the eastern coast of Greenland. This causes increased sea ice concentration and a temperature drop southeast of Greenland.

We acknowledge the critical use of a modern calender in our mid-Holocene comparison, instead of a calendar of angular months, defined by 12 times $30^{\circ}$ sectors on the Earth's orbit (Joussaume and Braconnot 1997). This is in particular crucial when comparing results for October, because the calendar is fixed at the vernal equinox and due to Kepler's laws, the length of the season varies with the precession cycle. Nonetheless, Joussaume and Braconnot (1997) stated that a relevant part of their 1-2 K difference of September air temperature difference caused by the different calendar methods is connected with the prescribed modern cycle of SST. Since our AOGCM calculates the seasonal cycle of SST dependent of the changing insolation signal, we do not expect significant inconsistency of our results due to the use of a modern calendar. Moreover, since the begin of the astronomically defined "October" at 6 kyr BP is shifted by 4 days into September (Joussaume and Braconnot 1997, their Table A1), the temperature difference in Fig. $7 b$ is even larger, when underlying the astronomical calendar.

\subsection{Holocene and twentieth century global warming trends}

In order to relate the Holocene climate evolution to the temperature trends of the last century we performed integrations with 


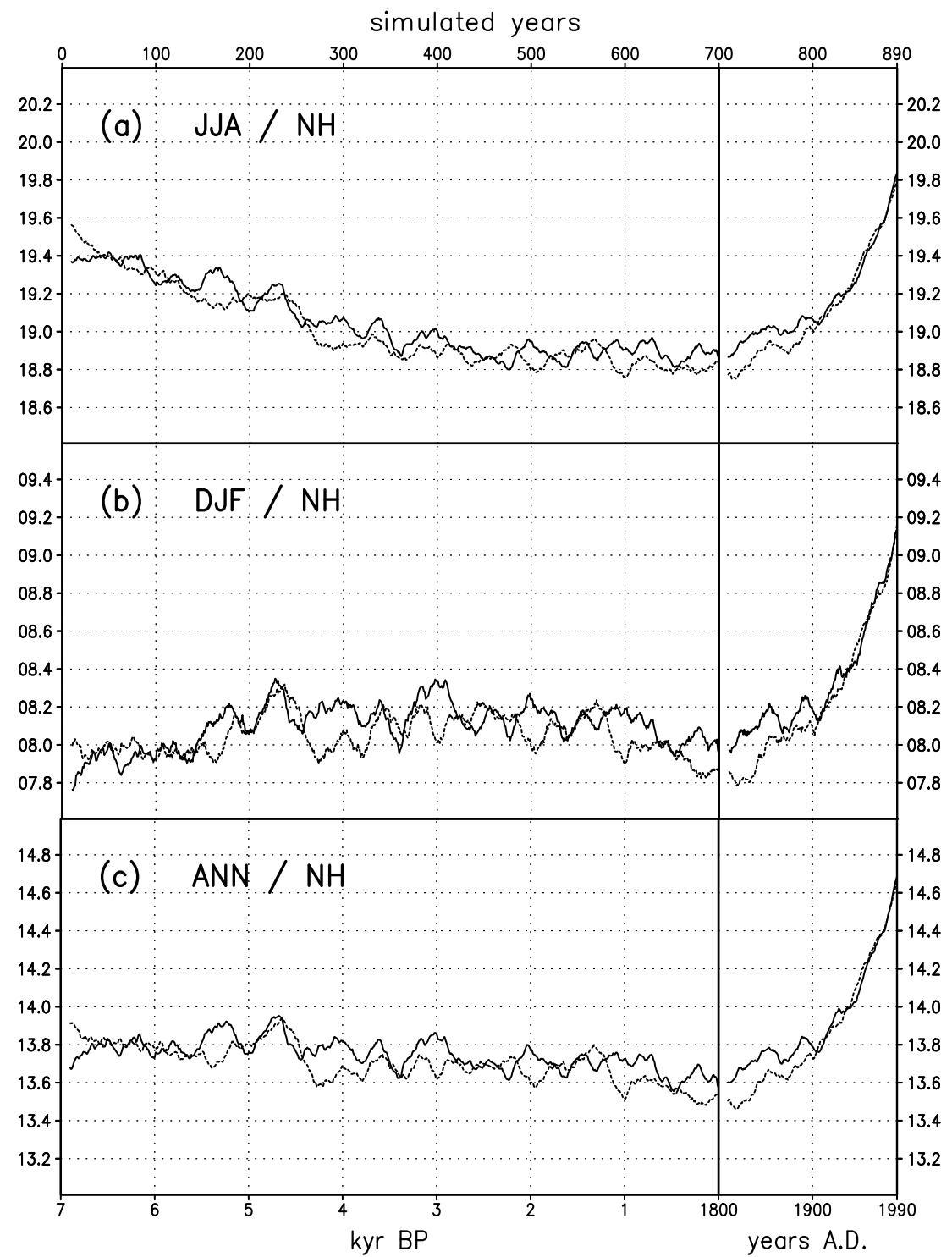

Figure 11. Temporal evolution of surface temperature (in ${ }^{\circ} \mathrm{C}$ ) of the Northern Hemisphere in (a) summer, (b) winter, and the (c) annual mean. The left part indicates two experiments (acceleration factor 10, HOL-INS10) from $7 \mathrm{kyr}$ BP to the latest Holocene (1800 AD), the right part displays the continuation of these experiments into the anthropogenic era until today (2000 AD), without using the acceleration technique for the Milankovitch forcing (experiment GHG-INS1, note the simulation time on the upper axis). The gap in the data is due to the application of a centred running mean filter of 21 simulation years that suppresses the appearance of the first 10 years of the experiments. A range of $2 \mathrm{~K}$ is used for all three ordinates.

historical evolution of greenhouse gases for the period year 1800 until $2000 \mathrm{AD}$. These simulations are continued from the two realisations of Holocene experiments HOL-INS10 without acceleration, since the greenhouse gas forcing provides a strong forcing on the time scale of the atmosphere-ocean-sea ice system. Fig. 10 shows a smooth transition between the surface temperature of the HOL-INS10 and GHG-INS1 experiments, when changing the acceleration factor for the orbital forcing from 10 to no acceleration.

Fig. 11 displays the temperature evolution of the Northern Hemisphere from 7 kyr BP until today. For the boreal summer, a long-term cooling trend during the Holocene until the begin of the anthropogenic area is detected. This cooling trend is of the same order of magnitude as the warming from the period 1800 to approximately $1950 \mathrm{AD}$ in the model. We note, however, that the recent warming trend is overestimated in the experiment, which is probably linked to the missing cooling effect of aerosols in the utilised version of the ECHAM4 model. For boreal winter, Fig. 11b indicates a small Northern Hemisphere cooling trend after 3 kyr BP, linked to the forcing by the precessional cycle in tropical latitudes (cf. Fig. 2df). Due to the spatial heterogeneity in the annual mean surface temperature trends, as seen in Fig. 4, the Northern Hemisphere surface temperature cooling trend during the Holocene is small when comparing it with the recent global warming trend (Fig. 11c).

When passing over to spatial signatures at northern high latitudes for October, differences between the climates at $6 \mathrm{kyr}$ BP and present day (1950-1999 AD, including the anthropogenic warming) are displayed in Fig. 12. The deviation of the mid-Holocene temperature from the present day climate (Fig. 12a) shows warming over the Arctic Ocean but little change or weak cooling over the high latitude continents. The warmer temperature over the Arctic Ocean at $6 \mathrm{kyr} \mathrm{BP}$ corresponds with thinner sea ice, in comparison with both the pre-industrial climate ( 0 kyr BP, Fig. $7 \mathrm{c}, \mathrm{d})$ as well as with present day climate (Fig. 12b). Over the northern continents, the warming induced by the anthropogenic increase of greenhouse gases exceeds the orbitally forced cooling during the last 6,000 years 

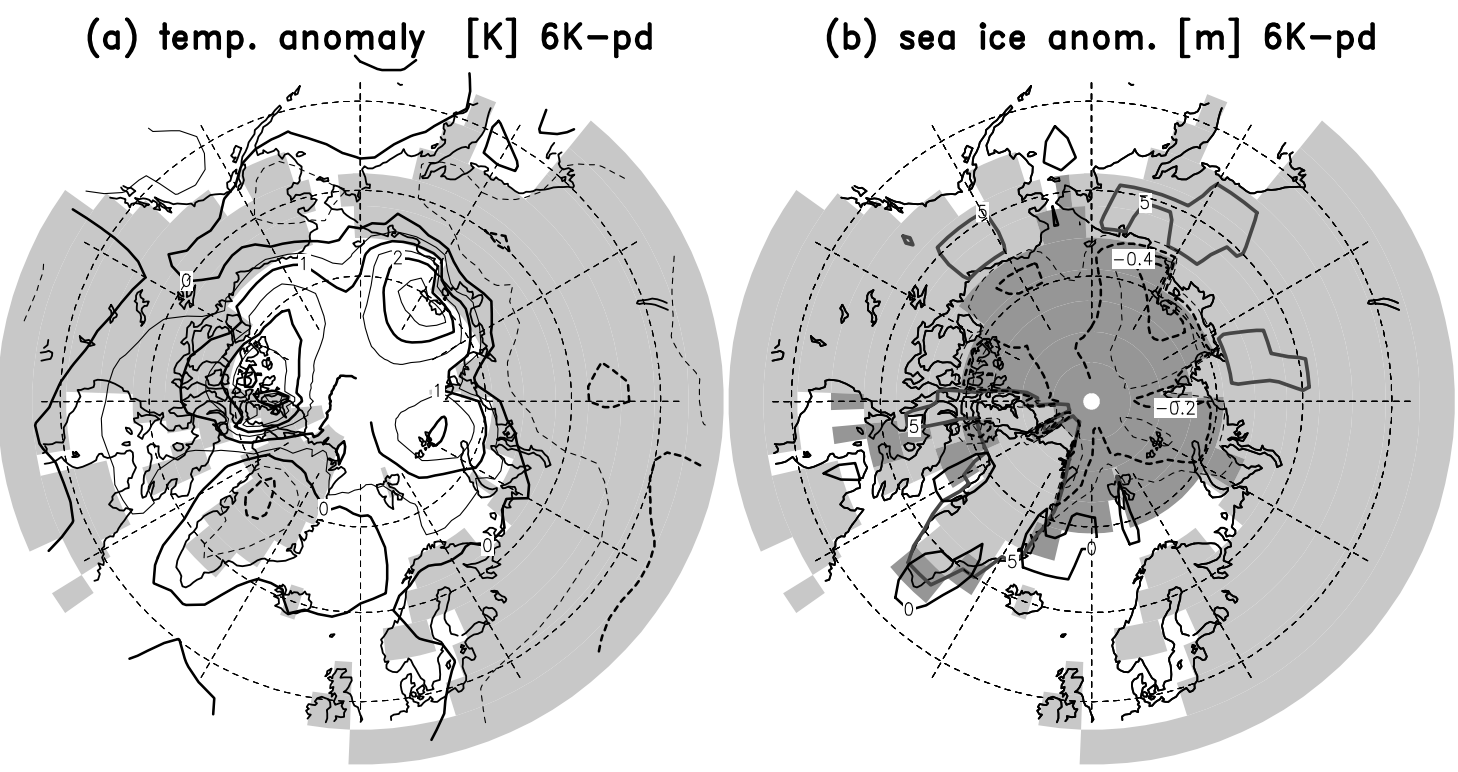

Figure 12. Difference of October near surface air temperature (a) and sea ice thickness (b) between the mid-Holocene climate at $6 \mathrm{kyr}$ BP and the present day climate. Analogue to Fig. 7b, d, areas where sea ice compactness in the present day climate exceeds $20 \%$ are darkly shaded, and the $5 \mathrm{~cm}$ contour line for snow depth in the present day climate is indicated with a thick grey line (no difference, cf. Fig. 7). Displayed is the average of 1950-1999 AD (50 years) of experiments GHG-INS1 for October.

until $1800 \mathrm{AD}$, which can be detected from a positive anomaly in Fig. $7 \mathrm{~b}$ (6 kyr BP minus 0 kyr BP). This results in lower temperatures at 6 kyr BP than today in Fig. 12a.

\subsection{Comparison with PMIP results}

In order to understand the physical mechanisms related to the precessional and obliquity cycles during the Holocene, we compare our transient mid-Holocene experiments with previous PMIP studies. At 6 kyr BP the precessional forcing was nearly in an opposite phase (the passage through the perihelion occurred in September compared to January today) of the 21,000 year period, which is the dominant period for tropical insolation changes. Within PMIP, simulations of the present day and the $6 \mathrm{kyr}$ BP climate were done with the former ECHAM3 atmospheric general circulation model (Roeckner et al. 1992). We show results of this model in Fig. 13, applying fixed vegetation distribution (Lorenz et al. 1996), and including an interactive vegetation model (Claussen 1997; Claussen and Gayler 1997). These authors coupled asynchronously a vegetation model with the ECHAM3 model. The model generates a climate in equilibrium with potential vegetation distribution and the boundary conditions for the middle Holocene. Prescribed sea surface temperature, orography, ice sheet distribution, insolation, and $\mathrm{CO}_{2}$ concentration were employed identically for both sets of simulations. The precessional forcing caused intensified precipitation and a shift of vegetation mostly in the southwestern part of the Sahara in this simulation. At high latitudes, the taiga extended northward at the expense of tundra during the mid-Holocen, when using the ECHAM3 including the vegetation model (Claussen and Gayler 1997; Claussen 1997).

The distribution of temperature difference for October, simulated with fixed SST (Fig. 13a), displays strong regional discrepancy with our study (Fig. 12a) using a coupled AOGCM. We note that the atmospheric temperature change induced by interactive vegetation (Fig. 13b) is in the same order of magnitude as the effect of the coupling to the ocean-sea ice system (compare Figs. 12a and 13a).

\section{Discussion}

Using our acceleration technique, we evaluated the temperature evolution of the Holocene and the last 200 years, a period of strong anthropogenic impact. The acceleration technique, the temperature trends, and the simulated mid-Holocene climate are discussed in the following.

\subsection{Acceleration technique}

The similarity in the results of the two sets of experiments when changing the acceleration factor places emphasis on the validity of the method. Therefore, our method of accelerating the orbital forcing in a complex AOGCM turns out to be a valuable tool to perform transient simulations of the Holocene climate.

The method is similar to distorted physics approach that is commonly applied for computer time reduction in ocean circulation models (Bryan 1984). In these ocean models the asynchrony lies in the separation of distinct ocean waves, which act on time scales of different orders of magnitude (Pacanowski et al. 1993). Another technique was introduced by Voss et al. (1998), using the ECHAM3 model coupled to the coarse resolution ocean circulation model LSG (Maier-Reimer et al. 1993). They based their asynchronous coupling on separated time scales of the atmosphereoceanic mixed layer and the deep ocean circulation. In their periodically-synchronous coupling technique the synchronously coupled model is integrated subsequently for 15 months, followed by an asynchronous phase of four years length, where the oceanic sub-model is calculated without the atmospheric sub-model (Voss and Sausen 1996; Voss et al. 1998).

We find no significant changes in the thermohaline circulation in our multi-decadal as well as in our centennial simulations (Fig. 5), which is consistent with the relatively stable climate during the middle to late Holocene period. For example, melting inland ice caps caused meltwater pulses including sea level rise. This may have provoked severe shifts of the thermohaline circulation during the early Holocene (e. g. during the Younger Dryas event). Although the astronomical forcing might be vigorous enough to effect changes in the location and strength of convection sites, there is no evidence in the marine geological record that the thermohaline circulation was subject to abrupt changes during the last 7,000 years (Grootes et al. 1993; Clark et al. 2002). Smaller rearrangements in the deep ocean circulation can modify regional trend patterns in particular near the Antarctic sea ice border and around Greenland (Fig. 4b).

\subsection{Temperature trends}

The subtropical warming trend from the middle to late Holocene is also consistent with SST reconstructions based on the alkenone 


\section{(a) temp. anomaly $[\mathrm{K}] 6 \mathrm{k}-\mathrm{pd}$}

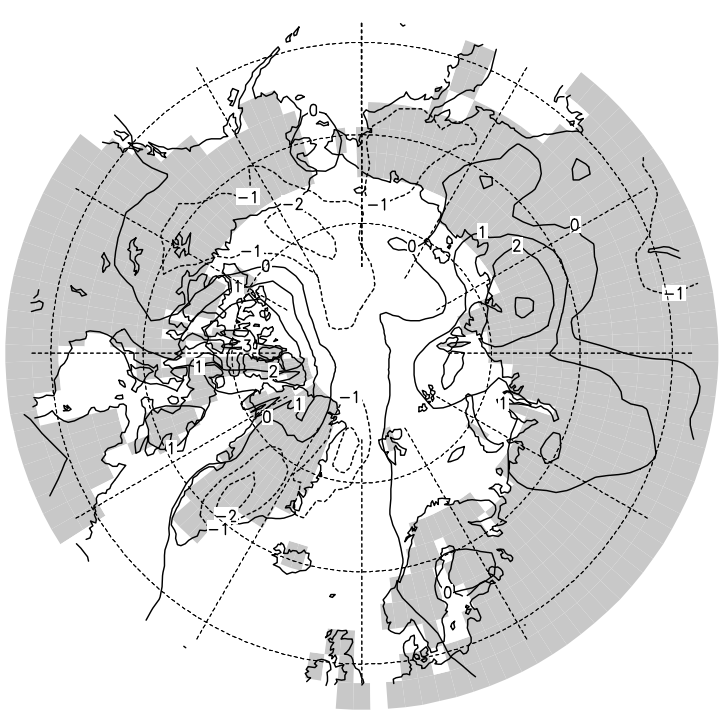

(b) temp. anomaly $[\mathrm{K}] 6 \mathrm{k}(\mathrm{veg})-6 \mathrm{k}$

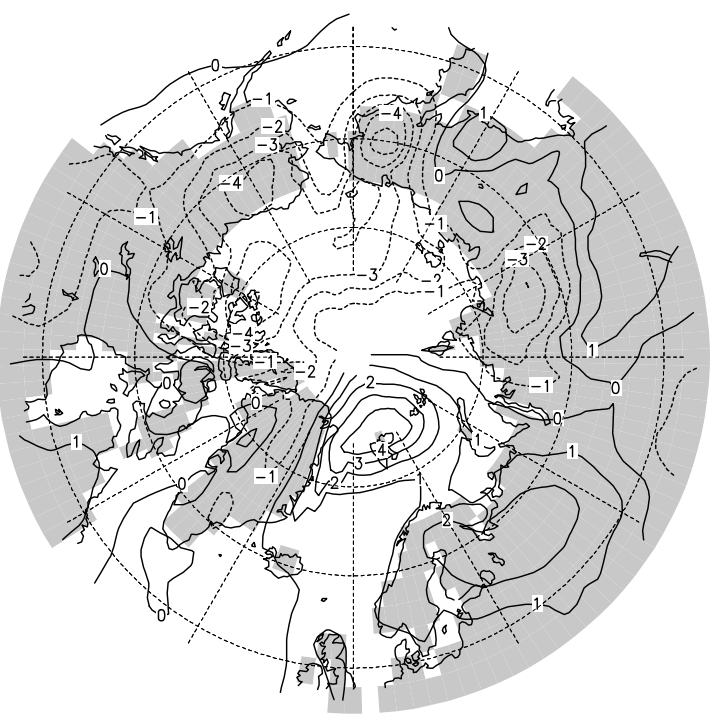

Figure 13. Near surface temperature of the simulation of the Holocene climate at $6 \mathrm{kyr}$ BP with the ECHAM3 atmosphere model, participating in PMIP. Shown is the mean temperature difference for October from simulations of the mid-Holocene climate applying fixed present day vegetation distribution (Lorenz et al. 1996), with respect to the present day climate (a), and the difference temperature calculating interactively the equilibrium potential vegetation distribution (Claussen and Gayler 1997), with respect to fixed vegetation (b) SST and sea ice distribution are fixed in these simulations (cf. Fig. 7).

method (Emeis et al. 2000; Marchal et al. 2002; Rohling et al. 2002). The spatial heterogeneity of the temperature trend in the North Atlantic realm (Fig. 4) is furthermore consistent with the SST signature of the Arctic Oscillation/North Atlantic Oscillation (AO/NAO, Thompson and Wallace 1998; Hurrell 1995), indicating a trend from a positive phase of the AO/NAO to a negative one during the Holocene. The AO/NAO phenomenon is the dominant mode of North Atlantic SST variability on inter-annual to decadal time scales. This surface temperature signature is consistent with proxy data (Rimbu et al. 2003). Along with the positive phase of the NAO, a temperature rise in Europe in the $6 \mathrm{kyr}$ BP climate are seen in the model results (Fig. 4b).

The trend in the AO/NAO from a more positive to a more negative phase, is possibly triggered by the boreal winter insolation. Since the precessional forcing is dominant in the tropics (Fig. 1), we speculate that the tropical Pacific provides for a rectification effect to the varying seasonal distribution of the solar radiation. The rectification is associated with an asymmetric response of the climate system to external forcing, such as e. g. the faster retreat than buildup of ice caps in the case of glacial-interglacial cycles (Imbrie et al. 1993), and a nonlinear response of a circulation model for the tropical Pacific Ocean to insolation forcing (Clement et al. 1999). In our case, the asymmetry is via the modes of atmospheric circulation: the insolation during the boreal winter season affects the atmospheric circulation on the Northern Hemisphere, thereby imprinting the typical AO/NAO temperature pattern (Thompson and Wallace 1998; Hurrell 1995; Rimbu et al. 2003).

In our experiments we find a continuous cooling trend during the last two millenia in the boreal winter season, which is less obvious in the annual mean $(0.4 \mathrm{~K}$ in the last 2,000 years mainly in the Northern Hemisphere). This cooling trend may also attribute to a millennial cooling trend as detected in Northern Hemisphere temperature reconstructions based on high resolution proxy data (Mann et al. 1999; Mann and Jones 2003). We note, however, that multidecadal to millennial climate variability could be strongly effected by other forcing mechanisms like solar radiation changes linked to sunspot variability and volcano activity affecting the atmospheric circulation (e. g. Crowley 2000; Shindell et al. 1999; 2001).
We extended our Holocene climate simulations into the period 1800-2000 AD, by including the forcing by the observed increase of atmospheric greenhouse gases. With this forcing we are able to relate the effect of the astronomical forcing to the temperature change influenced by anthropogenic emissions of greenhouse gases. We recognise the annual mean temperature trend during the last 200 years to be much larger than the trends induced by the Milankovitch forcing during the middle to latest Holocene.

\subsection{Mid-Holocene climate}

To avoid the use of prescribed SST, coupled atmosphere-ocean simulations of the mid-Holocene climate (Hewitt and Mitchell 1998; Voss and Mikolajewicz 2001; Kitoh and Murakami 2002) have recently been performed. These experiments simulate nearequilibrium states of the mid-Holocene climate (6 kyr BP), or perform a series of time slices stepping through the Holocene (Liu et al. 2003). Liu et al. (2003) using the time slice concept find also a cooling at low latitudes and a warming at higher latitudes during the Holocene and attribute this to direct radiation changes. Our method has been used to obtain the evolution of the Holocene climate related to modes of variability.

The pronounced warming in the Arctic Ocean at the midHolocene climate optimum, which is evident in our experiments, is supported by pollen and macrofossil proxy data (Texier et al. 1997) as well as by a northward shift of the Arctic tree-line (Tarasov et al. 1998). In the annual mean, we find a 1-2 K warming of the midHolocene temperature relative to today, which is smaller than for the June to October season (not shown). The annual mean highlatitude warming is a prominent feature in modelling experiments (Voss and Mikolajewicz 2001; Crucifix et al. 2002; Liu et al. 2003; Claussen et al. 1999, Kubatzki, pers. comm.). It can be attributed to the asymmetric response to the seasonal cycle of insolation forcing.

\section{Concluding remarks}

We investigate the impact of the slowly evolving change in the Earth's boundary condition during the Holocene, the annual distribution of incident solar radiation, on the climate of the coupled 
atmosphere-ocean-sea ice system. Justified by the much longer time scale of this astronomical forcing than that of the dynamical feedback processes in the atmosphere-ocean system we accelerate the time scale of the orbitally varying solar radiation (Berger 1978) by a factor of up to 100 . This enables the simulation of the middle to late Holocene period with a complex AOGCM. Furthermore, our approach allows for ensemble simulations of the Holocene climate in order to obtain the deterministic climate model response to external forcing. The advantage of our technique is that we included the feedbacks inherent in the AOGCM without changing the model code and the control climate.

The transient simulation of the Holocene climate renders a possibility to validate complex climate models with palaeoclimate proxy data, and furthermore, to separate between different forcing factors affecting Holocene climate trends. In a companion paper (Rimbu et al. 2004), we use our technique to compare the results with a new global set of collected marine proxy temperature data, based on the alkenone method. We obtain a coherent picture of neo-glaciation since $7 \mathrm{kyr}$ BP in the model and proxy data. We find opposite trends of warming and cooling occurring in the tropics and mid-latitudes. Performing new model experiments including other forcing mechanisms, model components, and feedbacks, such as the climate feedback induced by vegetation changes (e. g., Ganopolski et al. 1998a) could significantly extend our findings of a dominant orbital mechanism for Holocene surface temperature variations. Our acceleration technique has already been applied to the climate of the last interglacial (Eem, at 130-120 kyr BP) showing that the changes in the circulation and seasonal cycle are in accordance with high resolution proxy data (Felis et al. 2004).

In order to properly address the question, how increasing human population and industrialisation will induce a significant climate change, requires intimate knowledge on amplitude and rapidness in the natural variations of temperature or other temperature-related environmental properties. Unfortunately, historical records of direct temperature measurements that would allow consideration of changing climate on a global scale are too short and fall already within the period of strong human impact on natural conditions. The time period of the Holocene, which is prior to strong human impact, could be used as a basis for assessment of natural climate variability.

The models used in the IPCC process are clearly unrivaled in their ability to simulate a broad suite of variables across the entire world (IPCC 2001), but their reliability on longer time scales requires additional evaluation. We argue that the paleoclimate record of the Holocene provides an excellent test of these models on a quantitative basis. As a logical next step, we propose to continue simulations, which are validated with proxy data for the Holocene period, into the recent period of anthropogenic greenhouse warming with subsequent scenario integrations to simulate future climate change. This can enhance confidence into numerical projections of future climate change, and provide a better comparison of climate variability under natural and anthropogenic forcing.

Acknowledgments. We like to thank C. Heinze and J. Jungclaus and two anonymous reviewers for their helpful comments which improved the manuscript considerably. M. Claussen is acknowledged for providing us with part of the ECHAM3 data and S. Schubert for help with preparing Fig. 13. The model simulations have been done at the Deutsches Klimarechenzentrum (DKRZ), Hamburg, Germany. We thank S. Legutke for her support concerning the ECHO-G model experiments as well as the staff of the Max-Planck-Institut für Meteorologie and the DKRZ for technical support. This study was funded by grants from the German Ministry of Research and Education (BMBF) through the program DEKLIM.

\section{References}

Berger, A. L. (1978). Long-term variations of daily insolation and Quaternary climatic changes, J. Atmos. Sci., 35, 2362-2367.

Bertrand, C., M.-F. Loutre, and A. Berger (2002a). High frequency variations of the Earth's orbital parameters and climate change, Geophys. Res. Lett., 29, doi:10.1029/2002GL015,622.
Bertrand, C., M.-F. Loutre, M. Crucifix, and A. Berger (2002b). Climate of the last millennium: a sensitivity study., Tellus, 54A, 221-224.

Boden, T. A., D. P. Kaiser, R. J. Sepanski, and F. W. Stoss (1994). Trends '93: A compendium of data on global change, Carbon Dioxide Information Analysis Center ORNL/CDIAC-65, Oak Ridge National Laboratory, Oak Ridge, Tenn., U.S.A.

Boville, A. B., and P. R. Gent (1998). The NCAR climate system model, version one, J. Clim., 11, 1115-1130.

Bryan, K. (1984). Accelerating the convergence to equilibrium of oceanclimate models, J. Phys. Oceanogr., 14, 666-673.

Clark, P. U., N. G. Pisias, T. F. Stocker, and A. J. Weaver (2002). The role of thermohaline circulation in abrupt climate change, Nature, 415, 863-869.

Claussen, M. (1997). Modeling bio-geophysical feedback in the African and Indian monsoon region, Climate Dyn., 13, 247-257.

Claussen, M., and V. Gayler (1997). The greening of Sahara during the midHolocene: results of an interactive atmosphere-biome model, Global Ecol. and Biogeogr. Letters, 6, 369-377.

Claussen, M., C. Kubatzki, V. Brovkin, A. Ganopolski, P. Hoelzmann, and H. J. Pachur (1999). Simulation of an abrupt change in Saharan vegetation in the mid-Holocene, Geophys. Res. Lett., 24, 2037-2040.

Claussen, M., et al. (2002). Earth system models of intermediate complexity: Closing the gap in the spectrum of climate system models, Climate Dyn., 18, 579-586.

Clement, A. C., R. Seager, and M. A. Cane (1999). Orbital controls on the el nino/southern oscillation and the tropical climate, Paleoceanography, $14,441-456$.

CLIMAP Project Members (1976). The surface of the ice age Earth, Science, $191,1131-1137$

Crowley, T. J. (2000). Causes of climate change over the past 1000 years, Science, 289, 270-277.

Crucifix, M., M.-F. Loutre, P. Tulkens, T. Fichefet, and A. Berger (2002). Climate evolution during the Holocene: a study with an Earth system model of intermediate complexity, Climate Dyn., 19, 43-60.

Emeis, K.-C., U. Struck, H.-M. Schulz, R. Rosenberg, S. Bernasconi, H. Erlenkeuser, T. Sakamoto, and F. Martinez-Ruiz (2000). Temperature and salinity variations of Mediterranean Sea surface waters over the last 16,000 years from records of planktonic stable oxygen isotopes and alkenone unsaturation ratios, Palaeogeogr. Palaeoclimatol. Palaeoecol., $158,259-280$.

Etheridge, D. M., L. Steele, R. Langenfelds, R. Francey, J. Barnola, and V. Morgan (1996). Natural and anthropogenic changes in atmospheric $\mathrm{CO}_{2}$ over the last 1000 years from air in Antarctic ice and firn, J. Geophys. Res., 101, 4115-4128.

Etheridge, D. M., L. Steele, R. Francey, and R. Langenfelds (1998). Atmospheric methane between 1000 a.d. and present: evidence of anthropogenic emissions and climatic variability, J. Geophys. Res., 103, $15,979-15,993$.

Felis, T., G. Lohmann, H. Kuhnert, S. J. Lorenz, D. Scholz, J. Pätzold, S. A. Al-Rousan, and S. M. Al-Moghrabi (2004). Increased seasonality in Middle East temperatures during the last interglacial period, Nature, $429,164-168$.

Fichefet, T., S. Hovine, and J.-C. Duplessy (1994). A model study of the Atlantic thermohaline circulation during the last glacial maximum, Nature, $372,252-255$.

Ganopolski, A., and S. Rahmstorf (2001). Rapid changes of glacial climate simulated in a coupled climate model, Nature, 409, 153-158.

Ganopolski, A., C. Kubatzki, M. Claussen, V. Brovkin, and V. Petoukhov (1998a). The influence of vegetation-atmosphere-ocean interaction on climate during the mid-Holocene, Science, 280, 1916-1919.

Ganopolski, A., S. Rahmstorf, V. Petoukhov, and M. Claussen (1998b). Simulation of modern and glacial climates with a coupled global model of intermediate complexity, Nature, 391, 351-356.

Gates, W. L. (1976). The numerical simulation of ice-age climate with a global general circulation model, J. Atmos. Sci., 33, 1844-1873.

Grootes, P. M., M. Stuiver, J. W. C. White, S. J. Johnsen, and J. Jouzel (1993). Comparison of oxygen isotope records from the GISP2 and GRIP Greenland ice cores, Nature, 366, 552-554.

Grötzner, A., R. Sausen, and M. Claussen (1996). The impact of sub-grid scale sea-ice inhomogeneities on the performance of the atmospheric general circulation model ECHAM3, Climate Dyn., 12, 477-496.

Hewitt, C. D., and J. F. B. Mitchell (1998). A fully coupled GCM simulation of the climate of the mid-Holocene, Geophys. Res. Lett., 25, 361-364.

Hewitt, C. D., A. J. Broccoli, J. F. B. Mitchell, and R. J. Stouffer (2001). A coupled model study of the last glacial maximum: Was part of the North Atlantic relatively warm?, Geophys. Res. Lett., 28, 1571-1574.

Hoyt, D. V., and K. H. Schatten (1993). A discussion of plausible solar irradiance variations, J. Geophys. Res., 98, 18,895-18,906. 
Hurrell, J. W. (1995). Decadal trends in the North Atlantic oscillation: regional temperatures and precipitation, Science, 269, 676-679.

Imbrie, J., et al. (1992). On the structure and origin of major glaciation cycles: 1. linear responses to Milankovitch forcing, Paleoceanography, 7, 701-738.

Imbrie, J., et al. (1993). On the structure and origin of major glaciation cycles: 2. the 100,000-year cycle, Paleoceanography, 8, 699-735.

Indermühle, A., et al. (1999). Holocene carbon-cycle dynamics based on $\mathrm{CO}_{2}$ trapped in ice at Taylor Dome, Antarctica, Nature, 398, 121-126.

IPCC (2001). Climate Change 2001: the scientific basis, contribution of working group I to the Third Assessment Report of the IPCC, J. T. Houghton et al. (Eds.), Cambridge University Press, Cambridge, UK.

Joussaume, S., and P. Braconnot (1997). Sensitivity of paleoclimate simulation results to season definitions, J. Geophys. Res., 102, 1943-1956.

Joussaume, S., and K. E. Taylor (2000). The Paleoclimate Modeling Intercomparison Project, in Paleoclimate Modeling Intercomparison Project (PMIP): proceedings of the third PMIP workshop, Canada, 4-8 October 1999, edited by P. Braconnot, WCRP-111, WMO/TD-1007, pp. 9-24, World Meteorological Organization.

Keigwin, L. D., and R. S. Pickart (1999). Slope water current over the Laurentian Fan on interannual to millennial time scales, Science, 286, 520-523.

Kim, S.-J., G. M. Flato, G. J. Boer, and N. McFarlane (2002). A coupled climate model simulation of the Last Glacial Maximum, Part 1: transient multi-decadal response, Climate Dyn., 19, 515-537.

Kitoh, A., and S. Murakami (2002). Tropical Pacific climate at the mid-Holocene and the Last Glacial Maximum simulated by a coupled atmosphere-ocean general circulation model, Paleoceanography, 17, doi:10.1029/2001PA000,724

Lean, J., and D. Rind (1998). Climate forcing by changing solar radiation, J. Clim., 11, 3069-3094.

Legutke, S., and R. Voss (1999). The Hamburg atmosphere-ocean coupled circulation model ECHO-G, Technical Report 18, Deutsches Klimarechenzentrum, Hamburg, Germany.

Liu, Z., E. Brady, and J. Lynch-Stieglitz (2003). Global ocean response to orbital forcing in the Holocene, Paleoceanography, 18, doi:10.1029/2002PA000,819.

Lohmann, G., S. J. Lorenz, and M. Prange (2004). Northern high-latitude climate changes during the Holocene as simulated by circulation models, AGU monograph series, American Geophysical Union, accepted.

Lorenz, S., B. Grieger, P. Helbig, and K. Herterich (1996). Investigating the sensitivity of the atmospheric general circulation model ECHAM 3 to paleoclimatic boundary conditions, Int. J. Earth Sci., 85, 513-524.

Maier-Reimer, E., U. Mikolajewicz, and K. Hasselmann (1993). Mean circulation of the Hamburg LSG OGCM and its sensitivity to the thermohaline surface forcing, J. Phys. Oceanogr., 23, 731-757.

Manabe, S., and A. J. Broccoli (1985). A comparison of climate model sensitivity with data from the last glacial maximum, J. Atmos. Sci., 42, 2643-2651.

Mann, M. E., and P. D. Jones (2003). Global surface temperatures over the past two millennia, Geophys. Res. Lett., 30, doi:10.1029/2003GL017,814.

Mann, M. E., R. S. Bradley, and M. K. Hughes (1998). Global-scale temperature patterns and climate forcing over the past six centuries, Nature, $392,779-787$

Mann, M. E., R. S. Bradley, and M. K. Hughes (1999). Northern Hemisphere temperature during the past millennium: inferences, uncertainties, and limitations, Geophys. Res. Lett., 26, 759-762.

Marchal, O., et al. (2002). Apparent long-term cooling of the sea surface in the northeast Atlantic and Mediterranean during the Holocene, Quat. Sci. Rev., 21, 455-483.

Marsland, S. J., M. Latif, and S. Legutke (2003). Variability of the Antarctic circumpolar wave in a coupled ocean-atmosphere model, Ocean Dynamics, 53, 323-331

Milankovitch, M. (1941). Kanon der Erdbestrahlung und seine Anwendung auf das Eiszeitenproblem, 132, Royal Serb. Acad. Spec. Publ., Belgrad.

Pacanowski, R. C., K. D. Dixon, and A. Rosati (1993). The G.F.D.L. Modular Ocean Model users guide, GFDL Ocean Group, Technical Report 2, NOAA/Geophysical Fluid Dynamics Laboratory, Princeton, NJ.

Prange, M., G. Lohmann, and A. Paul (2003). Influence of vertical mixing on the thermohaline hysteresis: Analyses of an OGCM, J. Phys. Oceanogr. 33, 1707-1721.

Raible, C., U. Luksch, K. Fraedrich, and R. Voss (2001). North Atlantic decadal regimes in a coupled GCM simulation, Climate Dyn., 18, 321330.
Rimbu, N., G. Lohmann, J.-H. Kim, H. W. Arz, and R. R. Schneider (2003). Arctic/North Atlantic Oscillation signature in Holocene sea surface temperature trends as obtained from alkenone data, Geophys. Res. Lett., 30, $1280-1283$.

Rimbu, N., G. Lohmann, S. J. Lorenz, J.-H. Kim, and R. R. Schneider (2004). Holocene climate variability as derived from alkenone sea surface temperature and coupled ocean-atmosphere model experiments, Climate Dyn., in press, doi:10.1007/s00,382-004-0435-8.

Rodgers, K., P. Friedrichs, and M. Latif (2004). Decadal enso amplitude modulations and their effect on the mean state, J. Clim., in press.

Roeckner, E., et al. (1992). Simulation of the present-day climate with the ECHAM model: Impact of model physics and resolution, Report 93, Max-Planck-Institut für Meteorologie.

Roeckner, E., et al. (1996). The atmospheric general circulation model ECHAM-4: Model description and simulation of the present-day climate, Report 218, Max-Planck-Institut für Meteorologie.

Rohling, E., P. Mayewski, R. Abu-Zied, J. Casford, and A. Hayes (2002). Holocene atmosphere-ocean interactions: records from Greenland and the Aegean Sea, Climate Dyn., 18, 587-593.

Shin, S.-I., Z. Liu, B. Otto-Bliesner, E. C. Brady, J. E. Kutzbach, and S. P. Harrison (2003). A simulation of the Last Glacial Maximum climate using the NCAR-CCSM, Climate Dyn., 20, 127-151.

Shindell, D. T., D. Rind, N. Balachandran, J. Lean, and P. Lonergan (1999). Solar cycle variability, ozone, and climate, Science, 284, 305-308.

Shindell, D. T., G. A. Schmidt, M. E. Mann, D. Rind, and A. Waple (2001). Solar forcing of regional climate change during the Maunder Minimum, Science, 294, 2149-2152.

Shindell, D. T., G. A. Schmidt, R. L. Miller, and M. E. Mann (2003). Volcanic and solar forcing of climate change during the preindustrial era, $J$. Clim., 16, 4094-4107.

Sowers, T., R. B. Alley, and J. Jubenville (2003). Ice core records of atmospheric $\mathrm{N}_{2} \mathrm{O}$ covering the last 106,000 years, Science, 301, 945-948.

Stocker, T. F., D. Wright, and L. Mysak (1992). A zonally averaged, coupled ocean-atmosphere model for paleoclimate studies, J. Clim., 5, 773-797.

Tarasov, P., et al. (1998). Present-day and mid-holocene biomes reconstructed from pollen and plant macrofossil data from the former soviet union and mongolia, Journal of Biogeography, 25, 1029-1053.

Terray, L., S. Valcke, and A. Piacentini (1998). The OASIS coupler user guide, version 2.2, Technical Report TR/CMGC/98-05, CERFACS.

Texier, D., N. de Noblet, S. P. Harrison, A. Haxeltine, D. Jolly, S. Joussaume, F. Laarif, I. C. Prentice, and P. Tarasov (1997). Quantifying the role of biosphere-atmosphere feedbacks in climate change: coupled model simulations for 6000 years BP and comparison with palaeodata for northern Eurasia and northern Africa, Climate Dyn., 13, 865-882.

Thompson, D. W. J., and J. M. Wallace (1998). The Arctic oscillation signature in the wintertime geopotential height and temperature fields, Geophys. Res. Lett., 25, 1297-1300.

Voss, R., and U. Mikolajewicz (2001). The climate of 6000 years BP in near-equilibrium simulations with a coupled AOGCM, Geophys. Res. Lett., 28, 2213-2216.

Voss, R., and R. Sausen (1996). Techniques for asynchronous and periodically synchronous coupling of atmosphere and ocean models. Part II: impact of variability, Climate Dyn., 12, 605-614.

Voss, R., R. Sausen, and U. Cubasch (1998). Periodically synchronously coupled integrations with the atmosphere-ocean general circulation model ECHAM3/LSG, Climate Dyn., 14, 249-266.

Weaver, A. L., M. Eby, A. F. Fanning, and E. C. Wiebe (1998). Simulated influence of carbon dioxide, orbital forcing and ice sheets on the climate of the Last Glacial Maximum, Nature, 394, 847-853.

Wolff, J.-O., E. Maier-Reimer, and S. Legutke (1997). The Hamburg ocean primitive equation model HOPE, Technical Report 13, Deutsches Klimarechenzentrum, Hamburg, Germany.

Zorita, E., F. González-Rouco, and S. Legutke (2003). Testing the Mann et al. (1998) approach to paleoclimate reconstructions in the context of a 1000 -Yr control simulation with the ECHO-G coupled climate model, $J$. Clim., 16, 1378-1390.

S. J. Lorenz, Max-Planck-Institut für Meteorologie, Modelle und Daten, Bundesstraße 53, D-20146 Hamburg, Germany (e-mail: lorenz@dkrz.de). G. Lohmann, Universität Bremen, Fachbereich Geowissenschaften and DFG Forschungszentrum Ozeanränder Postfach 330 440, D-28334 Bremen, Germany (e-mail: gerrit@palmod.uni-bremen.de). 